\title{
Machine learning algorithm for prediction of stuck pipe incidents using statistical data: case study in middle east oil fields
}

\author{
Behzad Elahifar $^{1}$ (D) Erfan Hosseini $^{2}$ D
}

Received: 10 November 2021 / Accepted: 20 December 2021 / Published online: 7 January 2022

(c) The Author(s) 2022

\begin{abstract}
One of the most troublesome issues in the drilling industry is stuck drill pipes. Drilling activities will be costly and timeconsuming due to stuck pipe issues. As a result, predicting a stuck pipe can be more useful. This study aims to use an artificial intelligence technology called hybrid particle swarm optimization neural network (PSO-based ANN) to predict the probability of a stuck pipe in a Middle East oil field. In this field, a total of 85 wells were investigated. Therefore, to predict this problem, we must examine and determine the role of drilling parameters by creating an appropriate model. In this case, an artificial neural network is used to solve and model the problem. In this way, by processing the parameters of wells with and without being stuck in this field, the stuck or non-stuck of drilling pipes in future wells is predicted. To create a PSO-based ANN model database, mud characteristics, geometry, hydraulic, and drilling parameters were gathered from well daily drilling reports. In addition, two databases for directional and vertical wells were established. There are two types of datasets used for each database: stuck and non-stuck. It was discovered that the PSO-based ANN model could predict the incidence of a stuck pipe with an accuracy of over $80 \%$ for both directional and vertical wells. This study divided data from several cases into four sections: $17 \frac{1}{2 \prime} 2^{\prime \prime}, 11^{\prime \prime}, 8 \frac{1}{2} 2^{\prime \prime}$, and $61 / 8^{\prime \prime}$. The key reasons for sticking and the mechanics have been thoroughly investigated for each section. The methodology presented in this paper enables the Middle East drilling industry to estimate the risk of stuck pipe occurrence during the well planning procedure.
\end{abstract}

Keywords Stuck pipe · Particle swarm optimization · Directional wells $\cdot$ Daily drilling reports · Artificial intelligence technology

\begin{tabular}{|c|c|c|c|}
\hline \multicolumn{2}{|c|}{ Abbreviations } & NNs & Neural networks \\
\hline PSO & Particle swarm optimization & FFNN & Feed forward neural network \\
\hline AI & Artificial intelligence & EI & Each iteration \\
\hline ANNs & Artificial neural networks & SVM & Support vector machine \\
\hline MLP & Multilayer perceptron & MSE & Mean square error \\
\hline DDRs & Daily drilling reports & p best & Best position \\
\hline BHA & Bottom hole assembly & $\mathrm{g}$ best & Global best \\
\hline WOW & Waiting on weather & NW & North west \\
\hline BP & British petroleum & SE & Southeast \\
\hline OBM & Oil base mud & AJ & Aghajari formation \\
\hline LGS & Low gravity solid & MN & Mishan formation \\
\hline \multirow[t]{2}{*}{ MSA } & Multivariate statistical analysis & GS & Gachsaran formation \\
\hline & & CR & Cap rock formation \\
\hline \multirow{3}{*}{$\begin{array}{ll}\Delta & \text { Er } \\
& \text { e.l }\end{array}$} & Iosseini & As & Asmari formation \\
\hline & ini19@gmail.com & PD & Pabdeh formation \\
\hline & & GU & Gurpi formation \\
\hline \multirow{3}{*}{$\mathrm{D}$} & nent of Geoscience and Petroleum, Norwegian & IL & Ilam formation \\
\hline & ity of Science and Technology (NTNU), Trondheim, & SV & Sarvak formation \\
\hline & & SW & Southwest \\
\hline 2 & $\begin{array}{l}\text { ustries Engineering and Construction Company } \\
\text { Group), Tehran, Iran }\end{array}$ & KOP & Kick-off point \\
\hline
\end{tabular}




$\begin{array}{ll}\text { RIH } & \text { Run in hole } \\ \text { POH } & \text { Pull out of hole } \\ \text { W\&R } & \text { Wipe and ream } \\ \text { CSG } & \text { Casing } \\ \text { CONN } & \text { Connection } \\ \text { O.PULL } & \text { OVERPULL } \\ \text { BPH } & \text { Barrel per hours } \\ \text { LCM } & \text { Lost circulation material } \\ \text { COND } & \text { Condition } \\ \text { BTM } & \text { Bottom } \\ \text { BBL } & \text { Barrel } \\ \text { WT } & \text { Weight } \\ \text { DCS } & \text { Drill collars } \\ \text { P.LAX } & \text { Pipe Lax } \\ \text { CIRC } & \text { Circulation } \\ \text { DRLG } & \text { Drilling } \\ \text { O/P } & \text { Over pull } \\ \text { F.PIPE } & \text { Free pipe } \\ \text { G.OIL } & \text { Gas oil } \\ \text { W/ } & \text { With } \\ \text { GPM } & \text { Gallon per minute } \\ \text { GEL } & \text { Gelatin } \\ \text { AZ } & \text { Azimuth } \\ \text { AN } & \text { Angle } \\ \text { OH } & \text { Open hole } \\ \text { MD } & \text { Measured depth } \\ \text { TVD } & \text { True vertical depth } \\ \text { MW } & \text { Mud weight } \\ \text { PV } & \text { Plastic viscosity } \\ \text { YP } & \text { Yield point } \\ \text { TQ } & \text { Torque } \\ \text { CP } & \text { Circulating pressure } \\ \text { S } & \text { Stuck } \\ \text { NS } & \text { Non-stuck } \\ \text { NPT } & \text { Non-productive time } \\ & \end{array}$

\section{Introduction}

The most costly unplanned drilling occurrence for an operator is sticking a Drilling BHA, which results in the loss of equipment, hole footage, and maybe endangers well objectives. Stuck pipe events have the highest number of nonproductive times (NPT) in the drilling industry, ahead of well control incidents, waiting on the weather (WOW), lost circulation, equipment failures, and rig issues (Dushaishi et al. 2020; Amadi 2015). The annual cost to the industry is estimated to be in the billions of dollars (Hunter and Ollerenshaw, 2014). Today, one of the ways to predict drilling pipe stuck is to use artificial neural networks (Ahmadi and Chen, 2020). The particle swarm optimization (PSO) technique trains the multilayered feed-forward neural networks to discriminate the different operating conditions (Ahmadi
2012; Ahmadi et al. 2015). In 2007, Miri et al. conducted two models to predict differential sticking. They built the database model by creating 109 datasets representing 61 differentially stuck pipe incidents and 48 non-stuck pipe events. The following drilling parameters are included in the database model's input parameters: differential pressure, hole depth, and mud characteristics (API fluid loss, solid percent, mud filtrate viscosity, plastic viscosity, yield point, initial gel strength, and 10 min gel strength). Researchers utilized a back-propagation method, multilayer perceptron (MLP), and radial basis functions (RBF) for feed-forward networks. The research found that these networks are validated after 3401 epochs for the MLP network and 4264 epochs for the RBF network, and they can estimate the error of around $1 \%$. They also discovered that the RBF model's test findings are more accurate than the MLP model's. Shadizadeh et al. used an artificial neural network to predict the probability of a stuck pipe in 2010. They tested their model on databases with a total of 275 cases in them. Datasets for the model were acquired from daily drilling reports (DDRs) in one of Iran's oil fields by Shadizadeh et al. There were 115 stuck cases and 160 non-stuck cases in the database. Non-stuck data were gathered when the wells were entirely safe and had not become stuck in the same broad operating zones. The created model produced a reasonable outcome, with over $90 \%$ accuracy. Incidents with stuck pipes occur all around the world. However, due to the nature and structure of drilled formations, certain areas are more damaged than others. Al Dushaishi et al. 2021 established a model that consists of easily adaptable logical requirements that forecast stuck pipe events and provide a suitable treatment to unstick the pipe. Using simple and limited input inputs, their created approach could predict stuck pipe incidents with a $90 \%$ accuracy. Their prediction accuracy for removing the clogged pipe was 84 percent for the stuck pipe remedy model. The proposed models for stuck pipe events and remedy forecasts provide logical criteria based on simple quantities that may be used quickly in that oil field. A stuck pipe occurrence in one of the Middle East oil fields is investigated in this research. Most of the drilled wells in this field, according to DDRs, have had at least one stuck difficulty during their drilling operation. This issue has shown itself in every aspect of the well profile. In this industry, the cause of stuck pipes is significantly different. Tight hole problems, differential sticking, hole cleaning, and geometry problems are the most common stuck in this discipline. According to DDRs in the desired oil field, the processes used to liberate pipes in some cases are exceedingly time-consuming and costly. In this field, optimizing drilling parameters, mud characteristics, and geometry factors to reduce the danger of sticking can save time and money. A total of 85 wells in this field are investigated in this study. The wellbore is divided into four portions: hole Sections. 17 1/2", 12 1/4", 8 1/2", and 6 1/8". 
The causes of becoming stuck are investigated in each area. This field also investigates the number of stuck cases for each Formation, the types of sticking, the procedures used to free the pipes, and the major reasons for getting stuck. After that, input parameters are chosen to build a model for predicting the chance of a stuck pipe in the desired field. Selected variables are normalized, and two databases for vertical and directional wells are created. Finally, in the vertical and directed wells database, an artificial Intelligence method integrating neural networks and particle swarm optimization (PSO) is used to predict stuck pipe probability. Artificial neural networks and swarm particle optimization are two machine learning approaches used in this study since they are both powerful prediction techniques. The classification of problems into stuck and non-stuck cases is done using a PSO-based ANN model. The output variable is stuck pipe probability, while the input variables are drilling, mud, geometry, and hydraulic parameters.

\section{Literature review}

One of the major early stuck pipe prediction techniques is multivariate statistical analysis. Historically this technique was developed in the 1930s. Using MSA to predict stuck pipe occurrences was initially brought by Hempkins et al. through research done in 1985. Hempkins et al. claimed that before 1985 there had not been any statistical analysis that could bring some study to stuck pipe avoidance. Their study was applied to wells in the Gulf of Mexico. One major drive that forced scholars in the oil industry to explore several proactive approaches to predict stuck pipe is the high rate of sticking problems in the early 1980s, especially in the Gulf of Mexico and North Sea (Hempkins et al.). The authors stated that, between 1981 and 1984, almost 131 stuck pipe incidents were reported in the Gulf of Mexico. The research of Hempkins et al. included 131 stuck pipe cases and 20 drilling variables. They utilized discriminant analysis to develop discriminant functions, equations derived from correlations based on relationships between dependent and independent drilling parameters that would lead to the stuck pipe. These functions are set to classify the input data according to values of their parameters into three groups: mechanical stuck, differential stuck, and non-stuck pipe. The authors found that discriminant analysis brought an 81-87\% success rate. In other words, the model can correctly classify the data into their predetermined groups by $81-87 \%$. In 1994, Biegler and Kuhn constructed a model that could predict stuck pipe using the same technique of MSA. Their model included physical parameters of stuck pipe and large drilling datasets. Biegler and Kuhn claimed that their model could predict or detect stuck pipes and identify the driving mechanism of pipe sticking. Thus, the current model can optimize the drilling parameters and lead to stuck avoidance. However, their model was limited to water-based mud, and commercial software was used to analyze the data. There were eight independent, meaningful physical variables selected for each well. The model can optimize these variables during well planning to minimize the risk of stuck pipes. Siruvuri et al., in 2006, were the first researchers who used artificial neural networks to predict stuck pipes. They claimed that neural network modeling could provide better and more accurate solutions for the problems associated with differential sticking events. The researchers constructed a database model that contained 200 datasets, where 120 were reported as differentially stuck pipe and 50 as non-stuck pipe. Also, 35 datasets were used for cross-validation. The remaining dataset rows were used for testing purposes. They separated your database to conduct studies for the waterbased and oil-based sticking phenomenon. The datasets belonged to different fields which are located in the Gulf of Mexico. The authors constructed a simple three-layer generalized feed-forward neural network model. The number of neurons in the first layer (input layer) is dictated by the problem considered and consist of ten processing element. The number of neurons in the second layer (hidden layer) is automatically adjusted according to the strength of the data. Finally, the output layer includes two processing elements: differential stuck or no-stuck. To assess the model prediction performance, the authors calculated and examined two quantitative measures for predicted accuracy calculated and examined: MSE and final MSE. Finally, they observed that the proposed model could approximate the error with $\pm 5 \%$. Additionally, Sirivuri et al. found that the accuracy of the predictive model depends on the size of the database and the variables selected for the analysis. Miri et al. (2007), conducted research that utilized two models to predict differential sticking. They collected data from 32 wells drilled in the Persian Gulf from different fields (Soroush, Norouz, Abouzar, Forouzan, Salman, Dena, Doroud) during 1998-2006 that experienced differential pipe sticking, and 31 wells that did not experience differential pipe sticking to construct the database for the neural network to predict the risk of differential pipe sticking. Most of the wells were side-tracked and horizontal, and stuck pipe events have occurred in reservoir layers of wells in which oil-based or synthetic drilling fluids were being used to drill. Scholars assumed that oil and synthetic fluids would perform the same. Therefore, the neural network database model will be prepared to study oilbased and synthetic drilling fluids together. They constructed a database model by formulating 109 datasets representing 61 differentially stuck pipe incidents and 48 non-stuck pipe incidents. Each of these datasets has been classified either as stuck or not-stuck. The input parameters of the database model include the following drilling parameters: differential pressure, hole depth, and mud properties (API fluid loss,

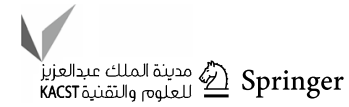


solid percent, mud filtrate viscosity, plastic viscosity, yield point, initial gel strength, and 10 min gel strength). They claimed that independence in the variable selection makes it possible to predict the occurrence conditions for the differentially stuck pipe. The output values range from zero to one, corresponding zero to non-stuck cases, and 1 to stuck issues. Values between zero and one roughly represent levels of risk. They divided your database into training, validation, and test data that assigned 85,5 , and 15 percent to the theme, respectively. Researchers used a back-propagation algorithm, feed-forward networks, multilayer perceptron (MLP), and radial basis functions (RBF). Both models, MLP and RBF, consisted of four layers. In their study, Miri et al. adjusted the number of neurons in each layer like before research (Sirivuri et al.). They applied two transfer functions TanhAxon and Linear Sigmoid Axon, to transform hidden and output layers. Results of the study showed that after 3401 epochs for MLP network and 4264 epochs for the RBF network, these networks are validated, and they can approximate the error of around $1 \%$. Also, they found that test results for the RBF model are more accurate than the MLP model. In 2009, Adriana et al. research presented a study of applying fuzzy logic concepts to the problem of differentially stuck pipes. They claimed that these methods could estimate the risk of stuck pipe occurrence in the well-planning procedure and during drilling in real time. Researchers made a database for their model that included three major data groups: mechanical, differential, and non-stuck. These groups form the basis of the entire Adriana et al. project analysis. They classified wells into 59 differentials, 68 mechanical stuck pipes, and 58 non-stuck as control input in the entire analysis. Also, Adriana et al. utilized discriminant analysis to generate a predictive model of group membership based on similar characteristics of each group. To reduce independent variables for the fuzzy input, they defined dimensionless groups. Consequently, they reduced input parameters from 18 variables into five dimensionless forms by combining initial parameters. They used a fuzzy model and neural network to predict stuck pipe occurrences and provide the optimal values of the variables necessary to move a well from the stuck region into the non-stuck area. In Adriana et al. models, the redefined variables were used as independent variables, and $F 1, F 2$ discriminant functions from the discriminant analysis were used as the control input. The data are divided by using $75 \%$ of the data for training and $25 \%$ data for checking. According to the outputs of their models, they found that the neural network had less misclassification than the fuzzy logic. In 2010, Shadizadeh et al. applied the artificial neural network to predict stuck pipe probability. They used their model on databases that involved a total number of 275 cases. Shadizadeh et al. collected datasets of the model from the daily drilling reports (DDRs) in one of the Iranian oil fields. The database contained 115 stuck and 160 non-stuck cases. Non-stuck data were collected from days that the wells were completely safe and had not become stuck in the same general areas of operation. Researchers selected input parameters between many parameters based on two criteria:

(1) There must be a spread of parameter values in the databases. This allows the neural network to approximate the function more easily.

(2) The variable must not be dependent on other input variables only. A parameter may depend on other input variables but must also be dependent on a parameter that is not an input variable.

According to the above criteria, some parameters were removed from the analysis. These parameters are WOB, CA, MW, true vertical depth (TVD), solid percent, flow rate, API fluid loss, loss at formation, and Pf. This study defined a new dimensionless parameter as geometric factor (GF) to reduce the remaining parameters. This parameter is related to geometry parameters and included several parameters. In this work, the available data have been normalized into the range of $0-1$, according to the drilling fluid condition in the different hole sections. They classified the study data into two groups: dynamic and static types. The drilling fluid is in circulation in dynamic conditions, while it is not circulating during static conditions. Finally, differential pressure, $\mathrm{pH}$, GF, RPM, ROP, and PV were considered for dynamic conditions. The final selected network has a three-layer feedforward and back-propagation with a sigmoid-type activation function in the hidden and output layers. The number of neurons in the input, hidden, and output layers is 6,3 , and 1 . The final parameters are differential pressure, GF, $\mathrm{pH}, \mathrm{YP}$, $\mathrm{PV}$, and GL. The final network is a three-layer feed-forward back-propagation network with correspondingly six, four, and one neuron in its input, hidden, and output layers. Activation functions are "tansig" and "logsig" in the hidden and output layers. The result of constructed model was reasonable with over $90 \%$ of accuracy. Al-Baiyat et al., in 2012, conducted research that included two models of machine learning to predict stuck pipe incidents. In addition to the neural network technique, Al-Baiyat et al. used another artificial intelligence method supporting vector machines (SVMs). The authors constructed a database that denoted as Group-X.

Datasets of Group-X were retrieved from the technical paper SPE 120128 by Murillo et al. 2009. The total number of selected datasets for learning in Group-X was 48 and 18 for testing. The datasets from Group- $X$ were sorted into testing or learning randomly but evenly distributed among the class labels. For Group-X datasets, each set had a target that is denoted by a stuck index as DS: differential stuck, MS: mechanical stuck, or NS: non-stuck. The constructed 
ANN model for this research was based on the multilayer perceptrons. Researchers built an ANN model for Group-X that was contained 18 neurons for the input layer since the number of parameters provided for that group is 18. Also, based on the optimization process, it has been found that the number of neurons in the hidden layer in the Group-X model was the number of inputs plus one, which was 19 in this case. Since the model will produce one class label for each dataset (either stuck or non-stuck), the output layer was designed to have a single neuron. The two most common activation functions in artificial neural networks were implemented; Sigmoid and Tanh. According to the sequence of activation functions, four scenarios in the ANN models were constructed for their project. They claimed that ANNs and SVMs are powerful tools for predicting stuck pipe incidents which are otherwise very complicated because of the number of variables. Also, the researchers have shown that machine learning techniques can predict the stuck pipe with reasonable accuracy, which is more than $83 \%$ based on the data that have been utilized. Al-Baiyat research showed that SVMs are more accurate in stuck pipe prediction than ANNs based on the data used. Another work in 2013 done by Chamkalani et al. demonstrated the usage of the support vector machine model to predict stuck pipe. A new model is developed using different wells' drilling parameters such as measured depth, mud weight, plastic viscosity, yield point, gel strengths, PH, and solid percent. The method incorporates hybrid least square support vector regression and coupled simulated annealing (CSA) optimization technique (LSSVM-CSA) for efficient tuning of SVR hyperparameters. The algorithm is applied to classify the stuck types, i.e., differential stuck or mechanical stuck. The data used for this study were collected from a Middle East oil field (Shoraka et al. 2011). Two hundred and nineteen sets of data were gathered in which non-stock had a portion of 109 data, mechanical acquired 51 datasets, and the remaining 59 data were allotted to differential sticking. The authors found that the model created in the study came up with a higher 95\% success rate to classify the data into three groups of stuck pipes.

\section{Geological settings}

\section{Field description}

The Dezful Embayment, which encompasses 45 oil fields and is frequently associated with gas caps, is one of the Middle East's most prolific locations. Aghajari, Ahwaz, Bibi Hakimeh, Gachsaran, Mansuri, Marun, and Rag-e Safid are all classified as supergiants since they contain 10 to 50 billion barrels of oil in place. Figure 1 depicts these oil fields. The desired oil field is the subject of this case study. In 1956,

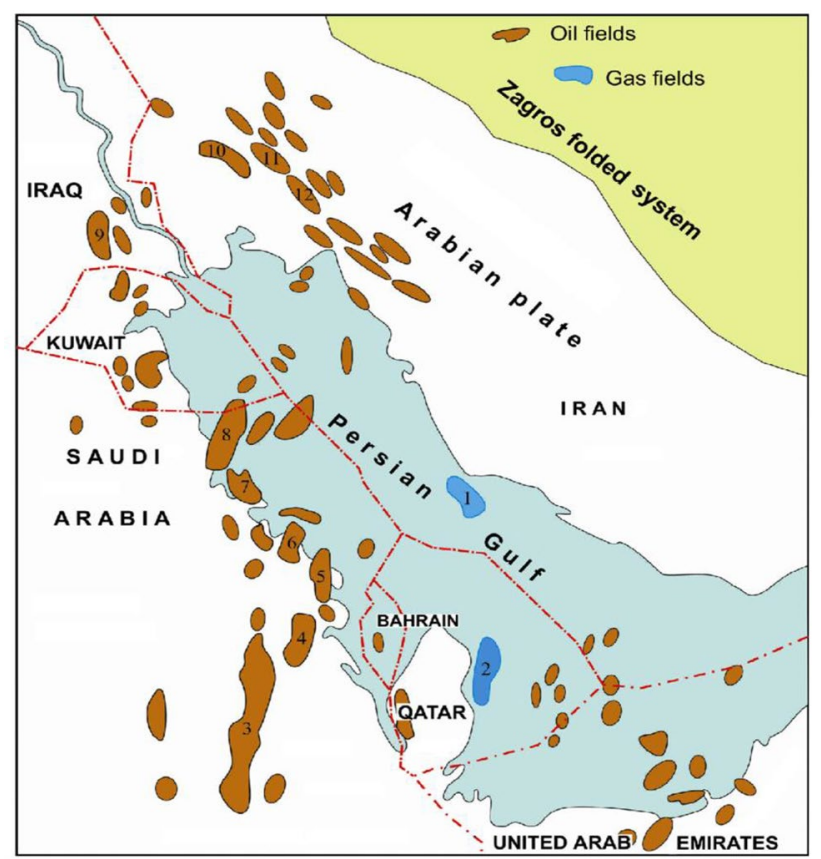

Fig. 1 Oil fields in Dezful Embayment, Middle East

the chosen oil field, one of the Middle East's most major supergiant oil fields, was discovered. This oil field is located in the southwest of Iran, in the center section of the north Dezful region. It features an anticline structure $72 \mathrm{~km}$ long and $6 \mathrm{~km}$ wide with an NW-SE trending symmetrical anticlinal. With 1,000,000 barrels per day, the Asmari Formation and Bangestan Group are its primary reservoirs.

\section{Well schematic and geological formations in desired oil field}

- The well design is chosen based on subsurface data such as formation pressures, strengths, constitution, cost goals, and drilling approach preferences. Figure 2 depicts a typical schematic of a well profile in the desired oil field. Figure 2 also shows that the well design consists of four

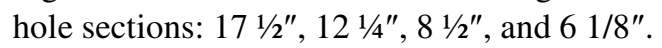

- A.J., MN, and GS7 formations are common in the 17 $1 / 2^{\prime \prime}$ hole sector. To isolate the $171 \frac{1}{2}$ " hole, a $135 / 8^{\prime \prime}$ casing shoe is put into the GS6 Formation. In the Dezful Embayment, the AJ Formation has the thickest layer. Silty marls, carbonated sandstones, and siltstones form up the upper part of AJ. This formation constitutes laminate red marls or gypsum veins, mud fissures, and grained siltstones. This formation is often drilled with 62-70 PCF water base mud. Gray marl with limestone blades includes the $\mathrm{MN}$ formation. With AJ, the upper contact surface is gradual, while the lower contact surface is very sharp and clear with GS. The GS7 formation

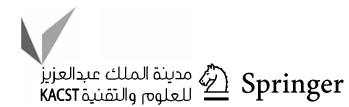




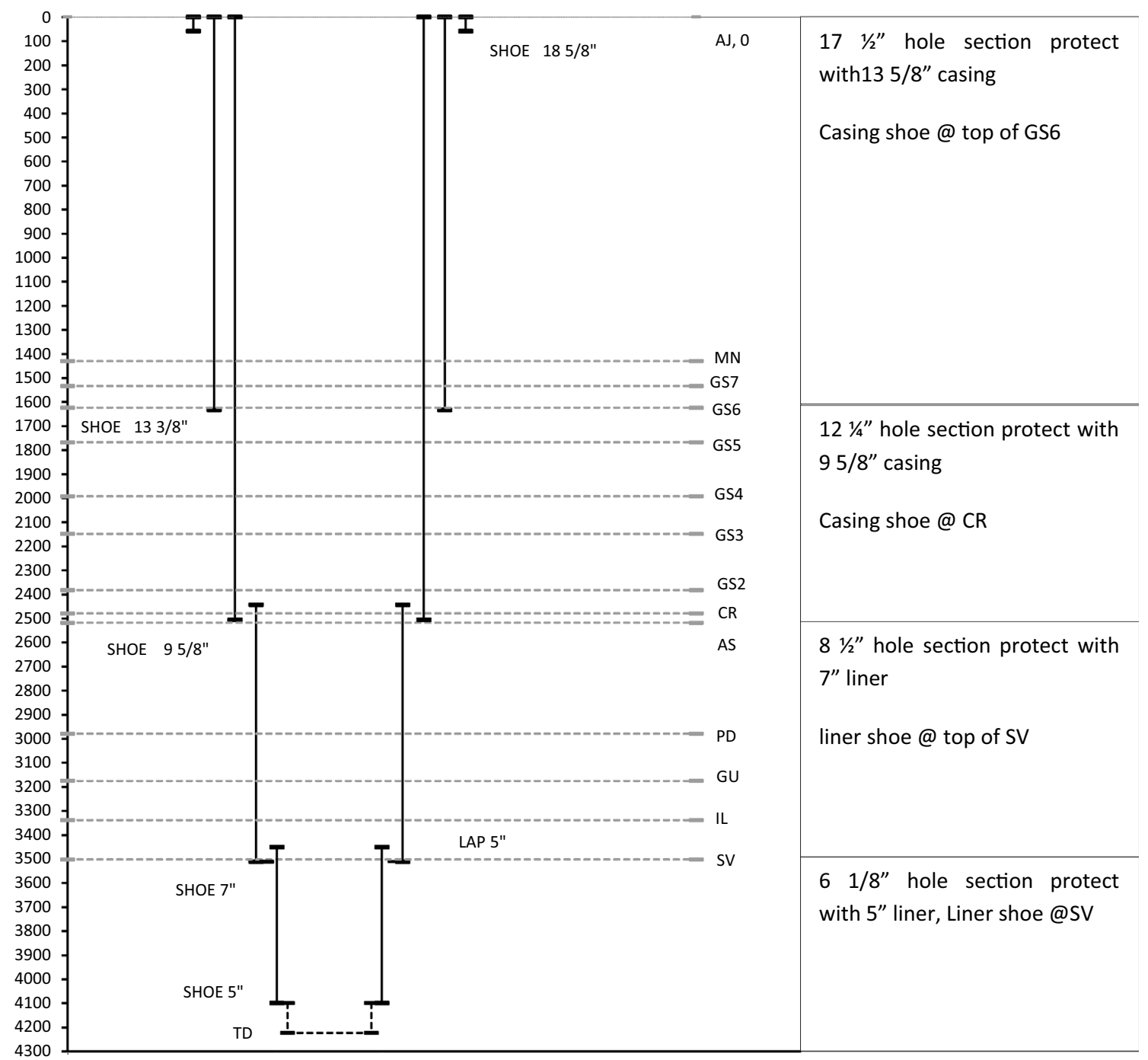

Fig. 2 Typical schematic of well profile in desired oil field, Middle East

comprises anhydrite, gray marl, and limestone at the top of the Gachsaran Formation. It has a thickness of nearly $92 \mathrm{~m}$ in the desired oil field. GS7 is usually under low pressure.

- From GS6 to CR, a 12 1/4" hole is drilled. This range contains the formations GS6, GS5, GS4, GS3, GS2, and CR. Isolate this hole with $95 / 8^{\prime \prime}$ casing before drilling an $81 / 2 "$ hole. Casing shoe is put in CR formation at 9 $5 / 8^{\prime \prime}$. The Gachsaran formation consists of evaporating anhydrite and salt with a small porosity and is deformable when compressed. There are seven members in the evaporating Gachsaran Formation. The Asmari Reservoir Formation's lowest member, member 1, is the caprock. Members 2 to 5 are particularly harmful due to the enormous pressures generated by the saline water it contains. Members 6 and 7 are usually under a lot of stress. As previously stated, the $135 / 8^{\prime \prime}$ casing shoe is put in the first layer of anhydrite at GS6.

- $\mathrm{CR}, \mathrm{AS}, \mathrm{PD}, \mathrm{GU}$, and IL formations are usually observed in the $8 \frac{1}{1 / 2}$ " hole section. A 7" liner guards this area. A 7" shoe indicates the top of the SV formation. Limestones, dolomitic limestones, and argillaceous limestones constitute the Asmari formation (one of the most well-known carbonate reservoirs in the world). The Asmari Formation, which ranges in thickness from 250 to $500 \mathrm{~m}$ and is rich in large Foraminifera, is a high-energy limestone with outstanding reservoir properties throughout the Dezful Embayment. A significant fracture system often improves reservoir quality near the tops of high-relief anticlines. The Asmari becomes sandy (Ahwaz Sandstone Member) at its base in the SW Dezful Embayment, increasing its porosity. The Gachsaran Formation is evaporated by the thick caps of the Asmari, forming 
a strong barrier. Asmari and Bangestan reservoirs in the Dezful Embayment oil fields are separated by the Pabdeh and Gurpi formations.

- On the other hand, these formations act as barriers for the Dezful Embayment's Bangestan reservoirs. These rocks can approximate marl or shale at times. Pabdeh formation consists of shale and clay-limestone. The Ilam Formation forms the upper part of the Bangestan reservoir. On the Ilam horizon, the Ahwaz Bangestan reservoir has a length of $75 \mathrm{~km}$ and a width of $8 \mathrm{~km}$. The Ilam Formation is made up of gray microcrystalline limestone that is thin to medium in thickness and is well-bedded. This layer is overlain by the Sarvak Formation and underlain by the Gurpi Formation.

- SV formation is drilled with a $61 / 8^{\prime \prime}$ section. A 5 " liner is used to seal this hole, and a $5 "$ liner shoe is placed at the bottom of the SV formation. The thick Sarvak limestone (300-1000 m thick) and the thinner Ilam Formation constitute the Bangestan reservoir (50-200 m thick). The thick Gurpi/Pabdeh marls covered these two reservoirs, creating a single reservoir in most Dezful Embayment. In southern Iran, the Sarvak Formation is one of the rock layers of the Bangestan group. This Formation's carbonate rocks are from the study field's reservoir rock.

\section{Methodology}

\section{Selecting and assembling data}

Preparing a database for machine learning models is a crucial step. Because noisy inputs result in poor model performance, the datasets must be accurate. A huge database also has a significant impact on the learning process. The model can be trained more effectively if the dataset is large enough. A total of 85 wells in this field were investigated in this investigation. Table 1 shows that 42 of the wells are vertical, whereas 43 are directional. In addition, 60 of the total wells were stuck at least once, while the other wells were drilled without issue. To create the model database, 230 sets were taken from daily drilling reports (DDRs) of the above wells, with 130 sets related to directional wells and 100 sets of data linked to vertical wells. There are 80 datasets of stuck instances and 50 datasets of non-stuck cases in

Table 1 Number of wells

\begin{tabular}{llll}
\hline Tittle & Vertical wells & $\begin{array}{l}\text { Directional } \\
\text { wells }\end{array}$ & Total wells \\
\hline Experienced stuck pipe & 30 & 33 & 63 \\
Observation wells & 12 & 10 & 22 \\
Total wells & 42 & 43 & 85 \\
\hline
\end{tabular}

the directional wells database. In addition, the vertical wells database has 50 datasets for stuck points and 50 datasets for non-stuck points, respectively. Non-stuck datasets were chosen from wells that did not report the problem of being stuck in their DDRs (22 wells that were drilled without issue). The control of model calculations will be based on these datasets. Table 2 shows the number of datasets for stuck and non-stuck wells according to well type. These datasets will be used in the modeling portion to create a PSO-based ANN model to predict stuck pipe probability in this field. These datasets will be used as input parameters for the learning process in this model. But first, according to DDR's expertise in this subject, the causes of this phenomenon are studied. As previously stated, the stuck problems have occurred in all portions of wells with hole sizes of $17 \frac{1 / 2 "}{2}, 12 \frac{1 / 4^{\prime \prime}, 8}{8}$ $1 / 2^{\prime \prime}$, and $61 / 8^{\prime \prime}$. Figure 3 a depicts the percentage of each hole size from the stuck incidence. Because each section has a unique geological condition, studying stuck pipe reasons is based on hole size. Drilling parameters, mud characteristics, and other drilling circumstances are also likely to differ from one hole section to the next. As a result, the size of the hole can be used to study stuck situations. It should be noted that the stuck pipe occurrence is a complex issue with numerous variables at play. However, this issue has been researched for each hole size, and the primary cause of sticking has been determined.

\section{Input parameters}

Drilling parameters, mud characteristics, geometry parameters, and hydraulic parameters were collected from DDR. The optimal input variables were chosen based on the causes of stuck pipes in this field. Additionally, to optimize the model's performance, the database was divided into two separate databases: vertical and directional wells. All of these characteristics have been chosen so that they are mostly selfcontained. Tables 3 and 4 illustrate these characteristics for vertical and directional cases, respectively.

\section{- Mud Weight (MW)}

As aforementioned, mud weight plays a critical function in all portions of the well. Additionally, differential sticking and tight hole problems, which are the most

Table 2 Number of datasets

\begin{tabular}{lcc}
\hline Tittle & Vertical wells & $\begin{array}{l}\text { Direc- } \\
\text { tional } \\
\text { wells }\end{array}$ \\
\hline $\begin{array}{l}\text { Stuck datasets } \\
\begin{array}{l}\text { Non-stuck datasets (observa- } \\
\text { tion data) }\end{array}\end{array}$ & 50 & 80 \\
Total data & 100 & 50 \\
\hline
\end{tabular}


Fig. 3 a Stuck pipe percentage for each hole size. b Stuck type percentage in $171 / 2^{\prime \prime}$ hole size. c Stuck pipe percentage for each formation in $171 / 2$ " hole size. d Stuck pipe percentage in $12 \frac{1 / 4}{\prime \prime}$ hole size. e Stuck pipe percentage for each formation in $121 / 4^{\prime \prime}$ hole size. f Stuck pipe percentage for each formation in $81 \frac{1}{2}$ " hole size. g Stuck type percentage in $8 \frac{1 / 2 "}{\prime \prime}$ hole size

prevalent types of stuck in this field, can be prevented with the proper mud weight. MW versus MD is displayed in Fig. 4 for both stuck and non-stuck cases in all depths of well. As illustrated in Fig. 5, MW for stuck situations is more strongly related to non-stuck issues at certain depth intervals (1000-2000 m and 3000-4000 m). Significant out-of-balance conditions at these intervals may result in differential sticking.

\section{- Solids level}

The kind and amount of solids in the cake determine its properties and the degree to which it sticks to the pipe. It should be noted that raising the cake thickness in a wellbore increases the chances of a stuck pipe. The solid $\%$ for stuck and non-stuck cases against MD is shown in Fig. 6. As illustrated in Fig. 7, between 3000 and 4200 m, the solid percent is more suitable for stuck difficulties.

\section{- Measured Depth}

In a stuck situation, the wellbore length can be an effective parameter. Greater strains will be put on the Formation at deeper depth, which could be a significant stuck pipe variable. Additionally, as drilling depth increases, drilling conditions become more difficult, increasing the danger of sticking. Figures 8 and 9 illustrate the number of stuck pipe-cases as a function of the MD interval between 0 and $500 \mathrm{~m}$ for vertical and directional wells. As shown in Figs. 10 and 11, most stuck cases occurred at depths greater than $3,000 \mathrm{~m}$ in vertical wells. In contrast, most of the stuck points occurred at greater depths than $2000 \mathrm{~m}$ in directional wells. Additionally, directional wells are shown to have more stuck problems at shallow depths than vertical wells.

\section{- Kick-off Point}

The kick-off point, or KOP, is defined as the point in the wellbore referred to as a vertical depth below the surface at which the well begins to deviate from vertical in a particular direction at a specific inclination and build-up angle. Generally, this is governed by the well targets and geological conditions. If the KOP is located at a shallow depth, the chance of sticking increases, as the directional section will be the well profile's longest section. In this field, wells identified with their KOP in the $17 \frac{1}{2} 2^{\prime \prime}$ hole section encounter more difficulties than wells located with their KOP in the $121 / 4$ " hole section.

\section{- Yield Point}

Y.P. represents the yield stress extrapolated to a zero shear rate. YP is used to determine a mud's ability to lift
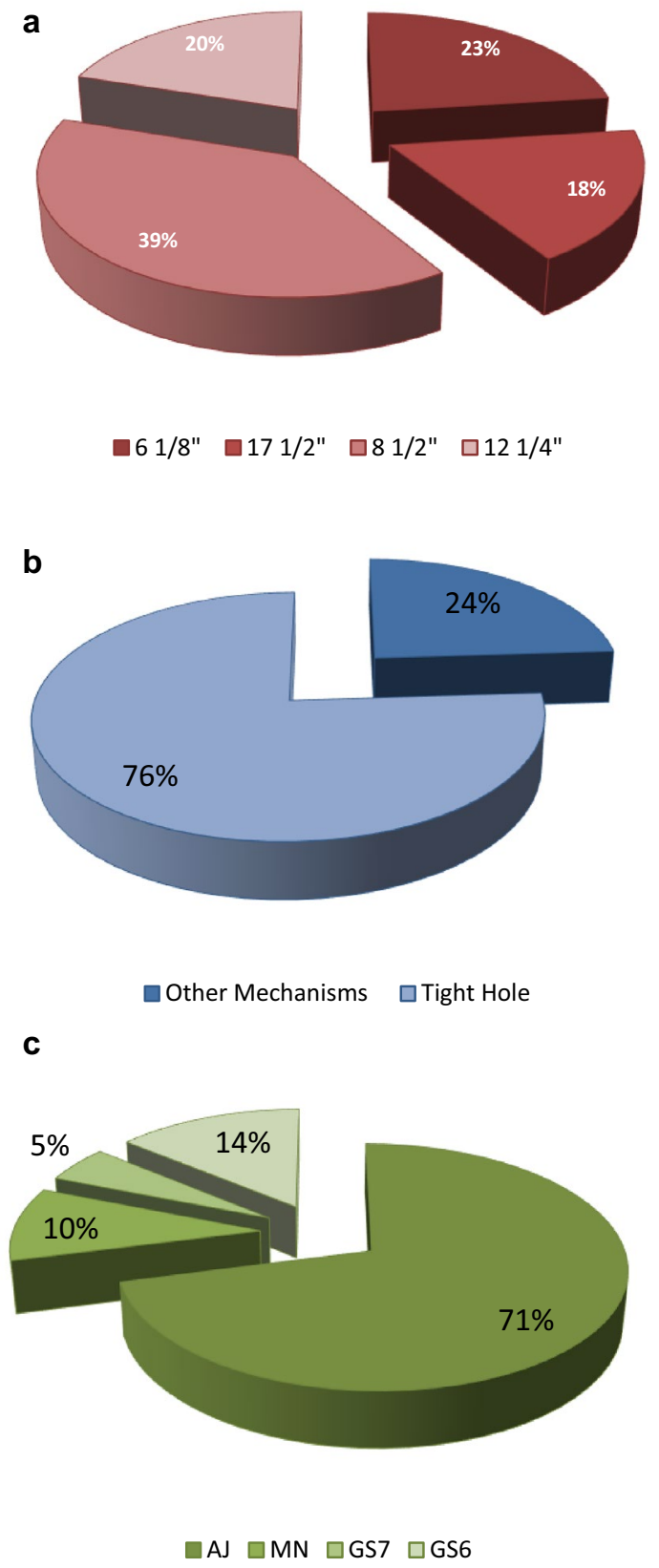

d

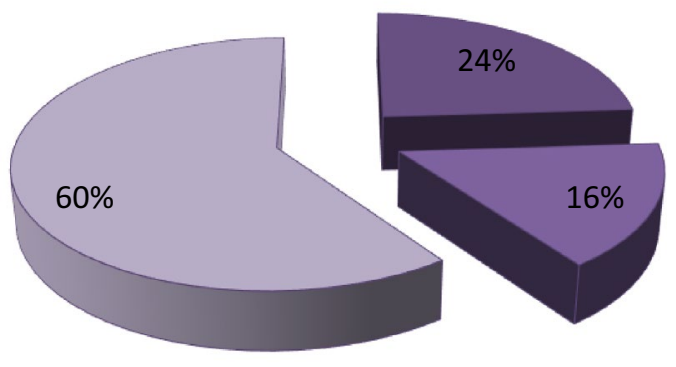

$\square$ Hole Cleaning $\square$ Differential Sticking $\square$ Tight Hole 
e

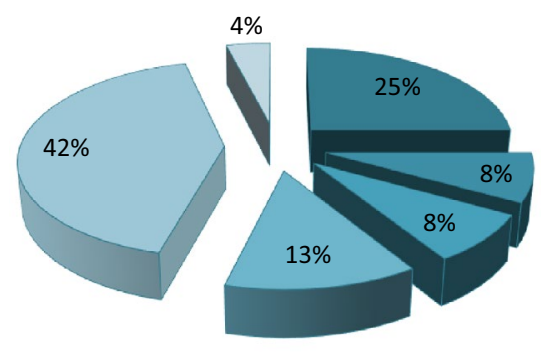

$\square \mathrm{CR} \square \mathrm{GS} 2 \square \mathrm{GS} 3 \quad \square \mathrm{GS} 4 \quad \square \mathrm{GS} 5 \square \mathrm{GS} 6$

f
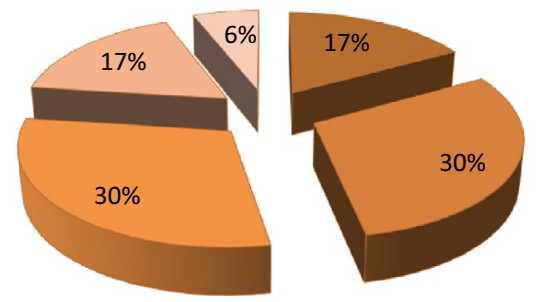

$\square \mathrm{SV} \square \mathrm{AS} \square \mathrm{IL} \square \mathrm{GU} \square \mathrm{PD}$

\section{g}
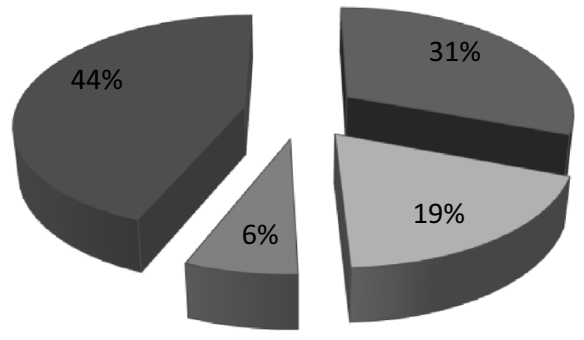

$\square$ Tight Hole $\quad \square$ Hole Cleaning
$\square$ Other Mecanism $\square$ Differential cuttings from the annulus. A high YP indicates a nonNewtonian fluid that transports cuttings more efficiently than a fluid of comparable density but lowers YP.

\section{- Plastic viscosity (PV)}

The slope of the shear stress/shear rate line above the yield point is indicated by PV. A low PV value implies that the mud can drill rapidly due to the low viscosity of the mud exiting the bit.

\section{- Gel Strength (Initial and $10 \mathrm{~min}$ )}

Shear stress is determined at a low shear rate after a mud has sat in a quiescent state for some time $(10 \mathrm{~s}$ and 10 min in the standard API procedure). Certain drilling fluids are thixotropic, gelling when left stagnant and liquefying when sheared. According to the measured gel strength versus time, a drilling fluid's specific gel strength is classified as low-flat (most desirable), progressive, or high-flat (both undesirable). It can be inferred that using the correct values for the YP, PV, and gel strength parameters results in improved hole cleaning and a reduced danger of sticking. It should be noted that the hole cleaning difficulty is one of the desired field's stuck mechanisms.

\section{- Revolutions per Minute (RPM)}

Increased rotational speed speeds up the process of straightening the drill collars. By increasing the RPM of the bit, more opportunities to cut the formation are produced in a given period. In the presented approach, the pipe being stuck is considered to be based on the specified parameter. This parameter is plotted versus MD in Fig. 9 for both stuck and non-stuck conditions. As indicated in Fig. 12, the RPM for stuck issues is lower than for non-stuck difficulties at shallow depths. However, at great depths, the RPM of non-stuck objects is significantly reduced.

Fig. 3 (continued)

Table 3 Selected parameters for vertical case

\begin{tabular}{llll}
\hline Parameters & Symbol & Unit & Category \\
\hline Hole size & Hole size & Inch & Geometry parameters \\
Depth of the last shoe & Last shoe & Meter & \\
The measured depth of stuck & MD & Meter & \\
Rate of penetration & ROP & ft/hr & Drilling parameters \\
Revolutions per minute & RPM & Round/min & \\
Pump Rate & GPM & Gallon/minute & Hydraulic parameters \\
Mud weight & MW & Pound per ft (PCF) & Mud properties \\
Plastic viscosity & PV & Centipoise & \\
Yield point & YP & Centipoise & \\
Gel strength (Initial and 10 min) & GEL & Centipoise & \\
Solid percent & Solid $\%$ & Percent & \\
\hline
\end{tabular}


Table 4 Selected parameters for directional case

\begin{tabular}{llll}
\hline Parameter & Symbol & Unit & Category \\
\hline Hole size & Hole size & Inch & Geometry parameters \\
Depth of the last shoe & Last shoe & Meter & \\
The measured depth of stuck & MD & Meter & \\
Kick-off Point & KOP & Meter & \\
Well Azimuth & AZ & Degree & \\
Hole Angle & AN & Degree & Drilling parameters \\
Rate of Penetration & ROP & ft/hr & \\
Revolutions Per Minute & RPM & Round/min & Hydraulic parameters \\
Pump Rate & GPM & Gallon/minute & Mud properties \\
Mud weight & MW & Pound per ft (PCF) & \\
Plastic viscosity & PV & Centipoise & \\
Yield point & YP & Centipois & \\
\hline
\end{tabular}

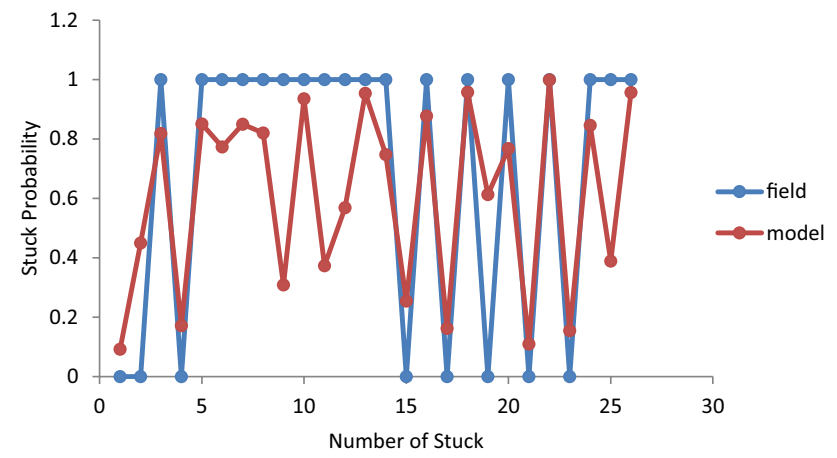

Fig. 4 Comparison of real and predicted results for testing data (directional wells)

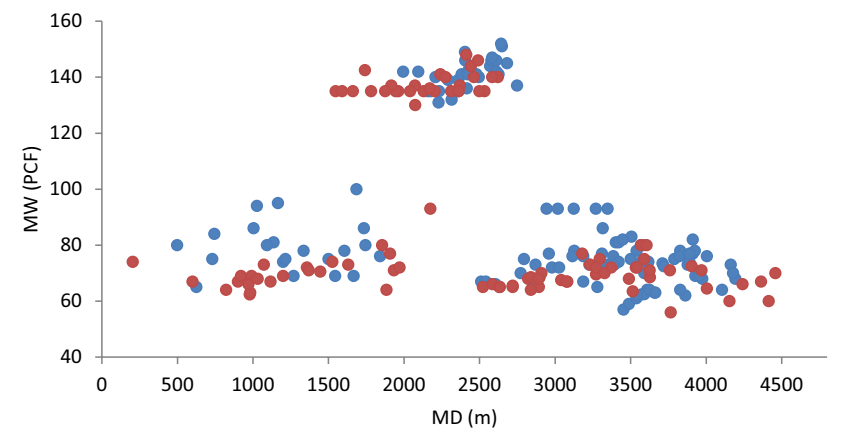

Fig. 5 Comparison of MW for stuck and non-stuck cases versus MD

\section{Redefining variables}

Combining input parameters is a typical data preparation approach in artificial intelligence methods. This combination should be straightforward and rational. In this work, several of the above parameters were reinterpreted as input variables for the user in the PSO-based ANN model. Six parameters

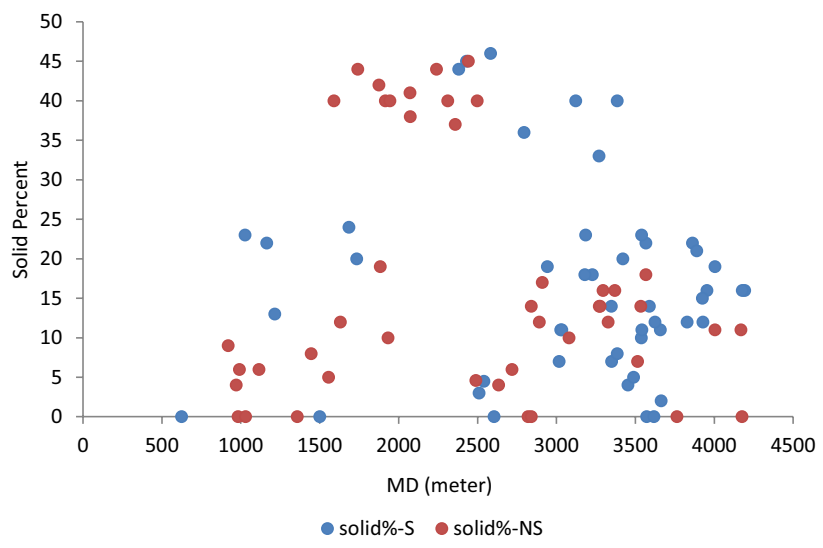

Fig. 6 Solid percent versus MD for stuck and non-stuck

have been redefined so that they become dimensionless factors. These are the following parameters: YP, PV, GL10M, GEL10 SEC, KOP, and last shoe. The following new parameters have been defined:

Open hole ratio $=\frac{(M D-\text { Last shoe })}{\text { M.D. }}=\frac{\mathrm{OH}}{\mathrm{MD}}$
Curve section ratio $=\frac{(\mathrm{MD}-\mathrm{KOP})}{\mathrm{MD}}$

Gelatin ratio $=\frac{\text { GL } 10 \mathrm{MIN}}{\text { GL 10SEC }}$

Viscosity ratio $=\frac{\mathrm{PV}}{\mathrm{YP}}$

Psically, it is evident that when the open hole ratio and curve section ratio rise, the risk of a stuck pipe increases. It is important to remember that this approach has been employed in past works. Shadizade et al. (2010), for 
Fig. 7 Comparison of real and predicted results for training data (vertical wells)
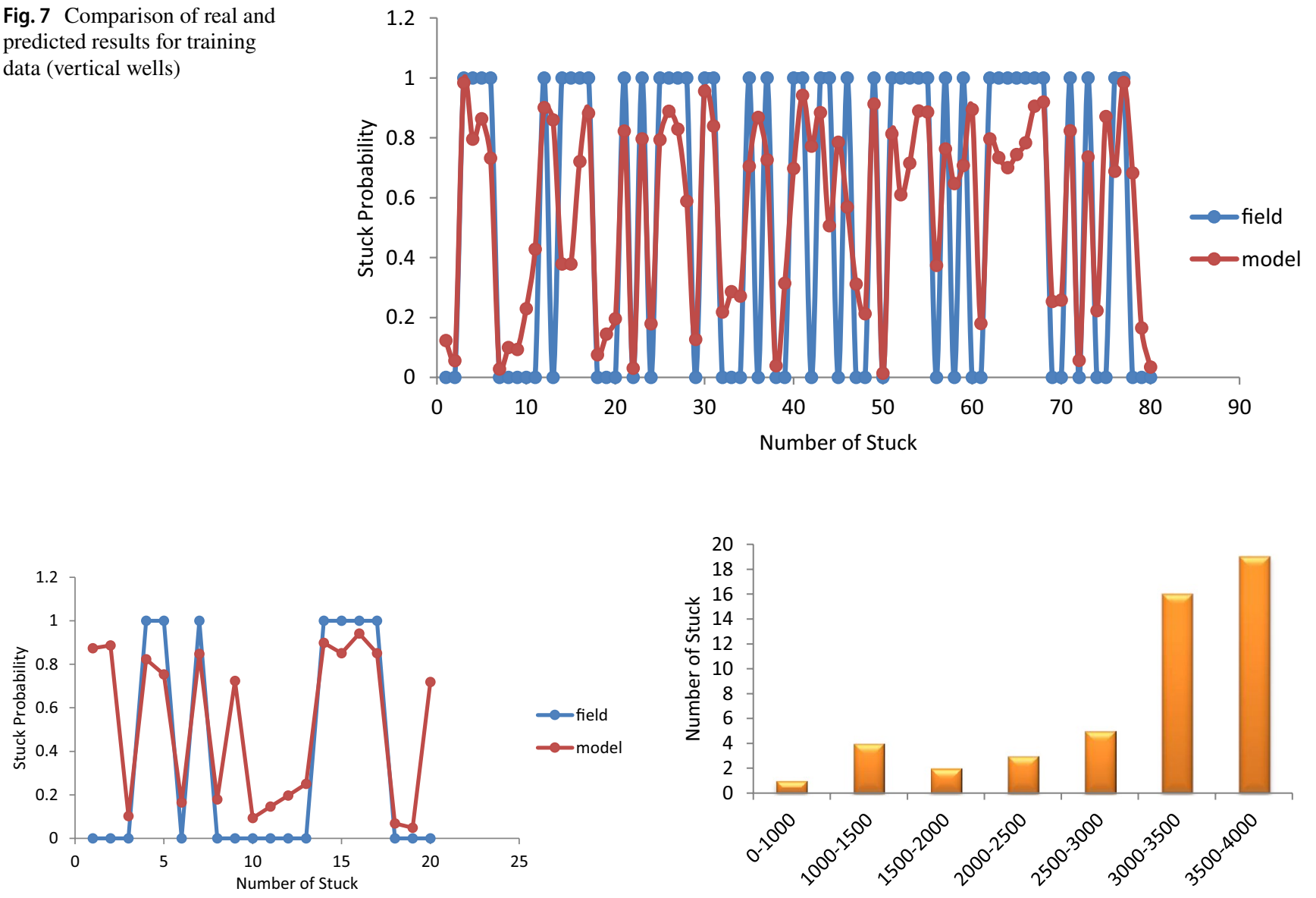

Fig. 8 Comparison of real and predicted results for testing data (vertical wells)

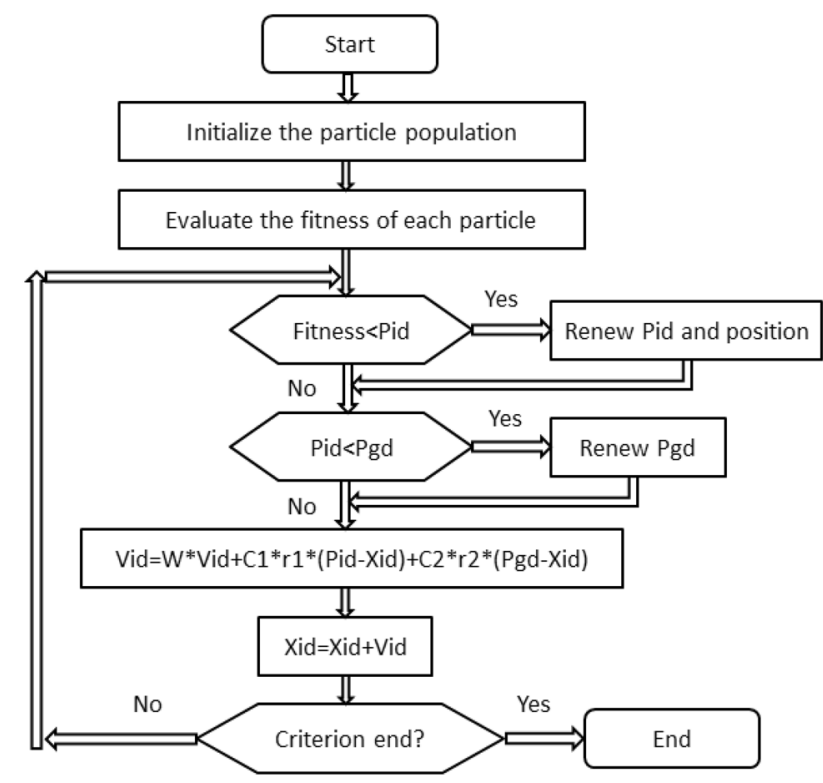

Fig. 9 The flowchart of PSO algorithm

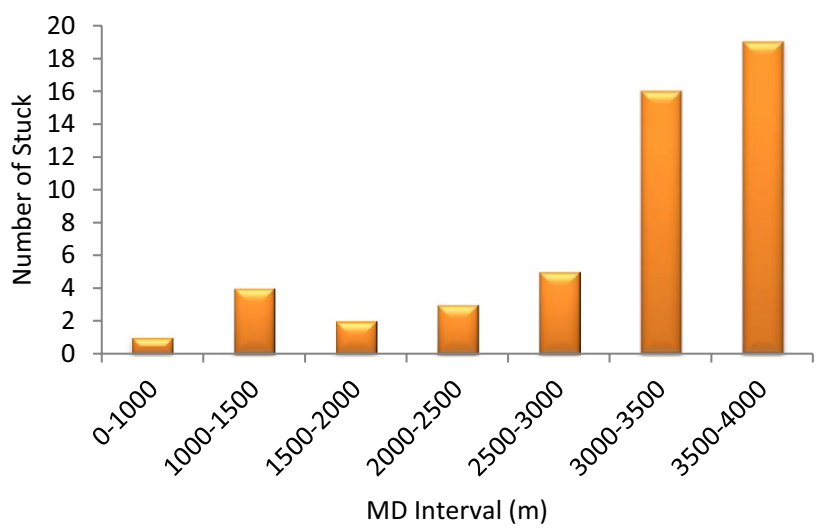

Fig. 10 The number of stuck versus interval MD for vertical wells

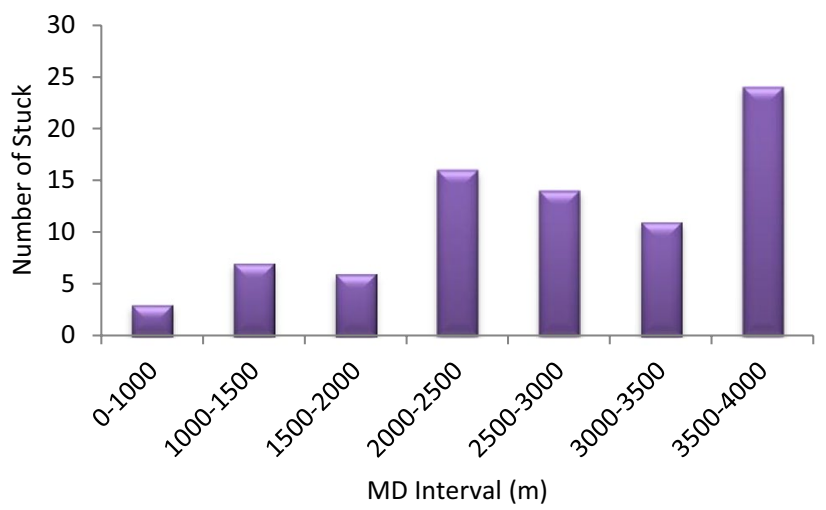

Fig. 11 Number of stuck versus interval MD for directional wells

example, used a parameter comprised of several simple geometry variables (geometrical factor). Additionally, Murillo et al. (2009) reduced independent variables for the fuzzy model using dimensionless groups. Murillo et al. transformed 18 variables into five dimensionless forms. Finally, 


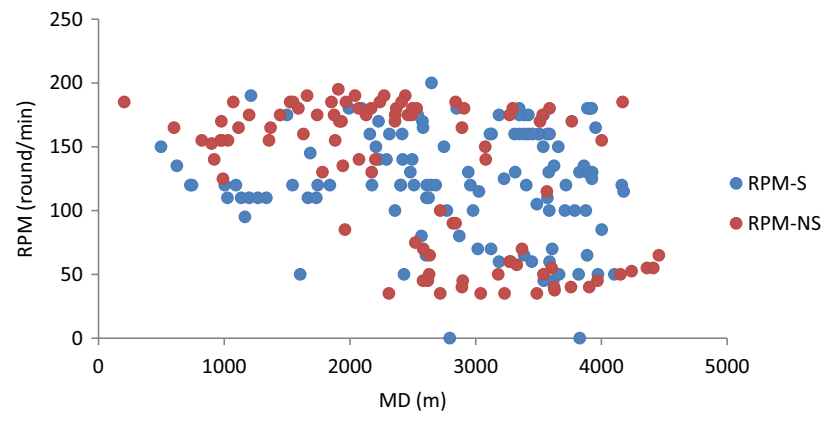

Fig. 12 RPM versus MD

the input parameters for the PSO-based ANN model were chosen to correspond to those listed in Table 5 for vertical and directional wells-along with the redefined variables listed in Table 6.

\section{Normalization}

Normalization of data refers to converting all variables in a database to a given range. When differences in variables have a negative impact on the model's performance, normalization is used. As illustrated in Table 7, the input parameters used in this investigation are quite varied. Thus, data normalization is critical in preprocessing the data for this investigation. Normalization of the database can ensure consistent convergence of weights and biases in ANN models. To normalize the input parameters in this research, the following formula was used:

$X(n)=\frac{X-X(\min )}{X(\max )-X(\min )}$

where $X(\mathrm{n})$ : normalized value, $X(\min )$ : minimum of original values, $X(\max )$ : maximum of original values, $X$ : original value.

This formula transforms all data to the interval between 0 and 1 . Table 7 illustrates the range of initial parameters for both database scenarios (vertical wells and directional wells).
Table 6 Redefined variables

\begin{tabular}{llll}
\hline Initially Variable & Unit & Redefined variable & Unit \\
\hline YP & CP & PV/YP & Dimensionless \\
PV & CP & & \\
GEL10MIN & CP & GEL10 MIN/GEL10 & Dimensionless \\
& & SEC & \\
GEL 10SEC & CP & & Dimensionless \\
MD & METER & OH/MD & \\
Last shoe & METER & & Dimensionless \\
MD & METER & (MD-KOP)/MD & \\
KOP & METER & & \\
\hline
\end{tabular}

Table 7 Range of parameters values for vertical and directional database

\begin{tabular}{|c|c|c|}
\hline Parameter & Minimum & Maximum \\
\hline \multicolumn{3}{|c|}{ Directional wells } \\
\hline HOLE PROB & 6.125 & 17.5 \\
\hline Last shoe & 56 & 4059 \\
\hline kop & 452 & 3777 \\
\hline Azimuth & 16 & 351.5 \\
\hline Angle & 1 & 88 \\
\hline ROP & 0.33 & 13 \\
\hline RPM & 35 & 200 \\
\hline GPM & 190 & 1350 \\
\hline MW Stuck & 60 & 152 \\
\hline PV & 0 & 98 \\
\hline YP & 0 & 33 \\
\hline MD Stuck & 204 & 4457 \\
\hline \multicolumn{3}{|l|}{ Vertical wells } \\
\hline HOLE PROB & 4.125 & 17.5 \\
\hline Last shoe & 56 & 4194 \\
\hline ROP & 0 & 12.27 \\
\hline RPM & 0 & 190 \\
\hline GPM & 0 & 1000 \\
\hline MW Stuck & 56 & 147 \\
\hline PV & 0 & 86 \\
\hline YP & 0 & 32 \\
\hline MD Stuck & 624 & 4192 \\
\hline SOLID $\%$ & 0 & 46 \\
\hline IN GEL & 0 & 14 \\
\hline 10MIN GEL & 0 & 18 \\
\hline
\end{tabular}

Table 5 Input parameters for PSO-based ANN model

Input parameters for PSO-based ANN Model

\begin{tabular}{|c|c|c|c|c|c|c|c|c|c|c|c|}
\hline Vertical Wells & Hole Size & $\mathrm{OH} / \mathrm{MD}$ & MD & ROP & RPM & GPM & MW & $\mathrm{PV} / \mathrm{YP}$ & GEL2/GEL1 & SOLID $\%$ & \\
\hline Directional Wells & Hole Size & $\mathrm{OH} / \mathrm{MD}$ & MD & ROP & RPM & GPM & MW & $\mathrm{PV} / \mathrm{YP}$ & (MD-KOP)/MD & $\mathrm{AZ}$ & AN \\
\hline
\end{tabular}




\section{Stuck pipe prediction using a hybrid PSO-based ANN}

A hybrid PSO-based ANN model was used to construct a model for predicting the chance of a stuck pipe. Particle swarm optimization (PSO) is being used in the study to train a feed-forward neural network to improve the convergence rate and learning process. The PSO algorithm is dependent on its implementation in two relationships:

$$
\begin{aligned}
V_{i d}= & w \times v_{i d}+c 1 \times r 1 \times\left(p_{i d}-x_{i d}\right) \\
& +c 2 \times r 2 \times\left(p_{g d}-x_{i d}\right)
\end{aligned}
$$

$X_{i d}=x_{i d}+v_{i d}$

where $c 1$ and $c 2$ are positive constants, $r 1$ and $r 2$ are random functions in the range $[0,1], x_{\mathrm{i}}=\left(x_{\mathrm{i} 1}, x_{\mathrm{i} 2}, \ldots, x_{\mathrm{id}}\right)$ represents the ith particle; $p_{\mathrm{i}}=\left(p_{\mathrm{i} 1}, p_{\mathrm{i} 2}, \ldots, p_{\mathrm{id}}\right)$ represents the ith particle's best previous position (the position with the highest fitness value); the symbol $g$ represents the index of the best particle in the population; and $v=\left(v_{\mathrm{i} 1}, v_{\mathrm{i} 2}, \ldots, v_{\mathrm{id}}\right.$ (Amin and Rodin 1998). The PSO algorithm's flowchart is depicted in Fig. 9. As previously stated, the primary objective of training ANNs with PSO is to get weights and biases that minimize the MSE. Particles move throughout the weight and bias space and update their positions during each iteration. The best error sets for the entire system are denoted by gbest, and the best error sets for each particle are indicated by pbest. Then, the ANN model is trained using the obtained particle positions, and the new error is calculated using new weights and biases until a sufficient mistake is found. Weights and biases are calculated and used for prediction.

\section{Test and train data}

As noted previously, two different database models were created to fund vertical and directional wells studies. The database is divided into subsets for training and testing. $80 \%$ of the dataset was used for training purposes for each database, and $20 \%$ was used to evaluate the model's performance. As shown in Table 8, 80 and 20 sets were assigned to training and testing data in vertical wells, respectively. There are 155 and 20 training and testing datasets for directional wells,

Table 8 Test and train data

\begin{tabular}{llc}
\hline Tittle & Vertical wells & $\begin{array}{c}\text { Direc- } \\
\text { tional } \\
\text { wells }\end{array}$ \\
\hline Training data & 80 & 104 \\
Testing data & 20 & 26 \\
\hline
\end{tabular}

respectively. The training and testing data percentages were determined randomly among all datasets in this analysis.

\section{Design of networks}

The optimal performance of the PSO-based ANN model can be reached by carefully selecting its parameters. As a result, numerous runs were conducted to determine the optimal parameters. The ANN model used in this study is based on multilayer perceptrons, which were addressed in the preceding chapter. It is worth noting that PSO can only change weights and biases to decrease learning error. In comparison, the network design (number of hidden layers and nodes within each hidden layer) must be optimized.

Number of neurons and layers The number of layers and neurons for each layer of the developed PSO-based ANN models are shown in Table 9. The input, hidden, and output layers are present in both cases. The input layer represents the problem's input parameters. As a result, the number of neurons in this layer equals the number of problem parameters. Because the number of parameters provided for this scenario is ten, the input layer in the model of the vertical well has ten neurons. To determine your total neural network architecture, you must first select the number of hidden neurons in a layer. Underfitting happens when there are not enough neurons in the hidden layers. Underfitting occurs when there are not enough neurons in the hidden layers to identify the signals in a complicated dataset (Chamkalani et al. 2013). Having too many neurons in the hidden layers might cause several problems. Overfitting may arise if there are too many neurons in the hidden layers. When a neural network has so much information processing capacity that the limited amount of data in the set is insufficient to train all neurons in the hidden layers, this is known as overfitting. Even when there is enough training data, a second issue can arise. Many neurons in the hidden layers can increase the time it takes to train the network. The network results showed that the eight hidden neurons have the best performance. There are numerous rule-of-thumb methods for finding the correct number of neurons to employ in the hidden layers. Here is a summary of a few of them: (Chamkalani et al. 2013).

- The number of hidden neurons should equal the difference between the input and output layer sizes.

- The number of hidden neurons should be $2 / 3$ the size of the input layer plus the output layer size.

- The number of hidden neurons should not exceed twice the size of the input layer. 
Table 9 Network architecture

\begin{tabular}{|c|c|c|c|c|c|}
\hline Tittle & Layers & Number of Neurons & Functions & Number of Particles & Iteration \\
\hline \multirow{5}{*}{ Vertical Wells } & Input layer & 10 & \multirow{3}{*}{ Hyperbolic Tangent } & \multirow{5}{*}{150} & \multirow{5}{*}{500} \\
\hline & & & & & \\
\hline & hidden layer & 7 & & & \\
\hline & & & \multirow[t]{2}{*}{ logistic } & & \\
\hline & Output layer & 1 & & & \\
\hline \multirow{4}{*}{ Directional Wells } & Input layer & 11 & \multirow{2}{*}{ Hyperbolic Tangent } & \multirow{4}{*}{200} & \multirow{4}{*}{500} \\
\hline & Hidden layer & 8 & & & \\
\hline & & & \multirow[t]{2}{*}{ Logistic } & & \\
\hline & Output layer & 1 & & & \\
\hline
\end{tabular}

However, the model was tested in the hidden layer with many neurons. Finally, the model of the vertical well produced the greatest results when seven neurons were counted in the hidden layer. The model will provide a single output for each dataset, a real number indicating the stuck pipe probability, resulting in a single neuron in the output layer. The number of neurons in the directional well model was $11,8,1$, and 1 neuron in the input, hidden, and output layers, respectively, in the same way, that they were for the vertical wells.

Activation functions Before training the model to add nonlinearity into the network, the transfer function at the active nodes of the feed-forward must be fixed. In practice, before training a neural network, the dataset must be preprocessed. The data are compressed during preprocessing to fit inside the activation function's active range. In neural network (NN) modeling, the activation function is crucial. Choosing the correct activation function for the $\mathrm{NN}$ design, on the other hand, is not critical (Al-Baiyat and Heinze, 2012). Many transfer functions have been developed; however, the two most popular neural networks are the logistic functions in artificial and hyperbolic tangent activation. As a result, these functions were used as a transfer function in both well datasets. The following equation gives the logistic activation function:

$f(x)=\frac{1}{1+e^{-x}}$

It is a sigmoid ( $S$-shaped) curve, and the outputs are in the range of $[0,1]$. Also, the hyperbolic tangent activation function is as follows: $f(x)=\frac{2}{1+e^{-2 x}}-1$

It is a sigmoid curve, similar to the logistic function. However, the output range is $[1,+1]$. Because of its symmetry, it frequently outperforms the logistic function.

Particle number and termination criteria While a small number of particles may fail to convert to a global solution, a large number of particles may cause convergence to be delayed and training time to be extended. Many runs were obtained because there is no theoretical study for determining the optimal number of particles. Increased particle sizes result in lower error values in the vertical well model. However, following a considerable improvement in network performance for swarm sizes of 10-150 particles, some minor variations in error values have occurred for swarm sizes bigger than 150 particles. On the other hand, the running time increases as the size of the swarm (number of particles) grows. As a result, in PSO-based ANN models for vertical wells, a value of 150 particles was chosen as the optimum number of particles.

In comparison, 200 particles were selected similarly for directional wells. The termination criteria are the circumstances that must be met for the iterative process to close. As a termination criterion in this study, the maximum number of iterations was chosen. As a result, the iterative process ends once the maximum number of iterations is achieved. Significant modifications were observed during the initial iterations according to the model's output. The variations in MSE values were reduced as the number of iterations rose.

Nonetheless, until iteration 500, the changes were moderate, and beyond that, the MSE fluctuations were minimal. As a result, the maximum number of iterations was chosen to be 
500. This termination condition concluded the iterative process when the maximum number of iterations was reached.

\section{Accuracy and error}

The network's output is usually in the [0 1] range. The data are classed as stuck cases if the result is larger than 0.5, and it is classified as non-stuck cases if the output is less than 0.5 . The inaccuracy is then calculated using a comparison of actual and expected work. The following is how the error is calculated:

Error $=$

The number of stuck data considered as non - stuck + The number of non - stuck data considered as the stuck total number of data reasons for a stuck pipe. Tight hole difficulties, differential sticking, hole cleaning, and incorrect well geometry are the most common stuck in this field. In this section, stuck pipe issues are investigated in all well hole sizes, and a model is developed to estimate stuck pipe probability in this field.

\section{Stuck problems in 17 1/2" hole size}

There were twenty-one total stuck incidents in this hole, with seven occurring in vertical wells and fourteen in directional wells. Figure $3 \mathrm{~b}$ shows that the tight hole mechanism is the
The accuracy of any model is determined by the number of outputs correctly identified throughout all datasets. As a result, the model's accuracy is calculated using the formula:

Accuracy $=\frac{\text { the number of data predicted correctly }}{\text { total number of data }}$

Another error function that has been used to determine the error of outputs in prior work is "Mean Square Error" or MSE, which is defined as the following formula:

$\mathrm{MSE}=\frac{1}{N} \sum_{1}^{N}(y-T)^{2}$

where: MSE $=$ Mean Square Error, stuck index ( 0 or 1 in this study), T: predicted stuck index (output of the model), $\mathrm{N}$ : total number of data for each case.

Because this is a classification problem, 10 and 11 formulas are more relevant for calculating error and accuracy than 12 .

\section{Results and discussion}

\section{Stuck pipe problem in desired oil field}

Stuck pipe problems are among the most difficult challenges to solve during a drilling operation at the desired field. According to DDRs, most drilled wells in this field have had at least one stuck pipe occurrence during their drilling operations. This issue has shown itself in every aspect of the well profile. The procedures and methods used in the desired field to free the pipelines are time-consuming and, in some cases, ineffective. Drilling parameters, mud characteristics, and geometry factors can all be optimized to reduce the chance of sticking and save time and money throughout the drilling operation. In this industry, there are various most common type of stuck pipe in this area. Most of the issues occurred during the wash and ream, surveying, connection, $\mathrm{RIH}$, and $\mathrm{POH}$ operations. Table 10 shows that most of the stuck scenarios in $171 / 2^{\prime \prime}$ hole sizes occurred in the AJ Formation. The AJ Formation had the most stuck cases, accounting for $75 \%$ of all cases in this section. According to DDRs and other data, the main reason for the stuck pipe in this part is as follows: Swelling of the AJ Formation can occur if the drilling duration in this hole is extended. While a result, like wash and ream, surveying, $\mathrm{RIH}$, and $\mathrm{POH}$ activities, is carried out across these swollen formations, the probability of a stuck pipe increases due to the downfall. Inappropriate mud and hydraulic parameters, on the other hand, have a significant impact on the stuck incidence in this hole. Table 11 contains more information on stuck cases in the 17 1/2" hole section. For each stuck example, the formation name, MD of stuck, KOP, hole angle, and stuck condition have been determined in these tables. In addition, the methods employed to release the pipes for each scenario were described. Figure $3 \mathrm{c}$ also shows the percentage of stuck pipe for each formation in a hole size of $171 / 2^{\prime \prime}$.

Table 10 Number of stuck pipe in 17 1/2" hole based on formation

\begin{tabular}{lccc}
\hline Formation & Vertical wells & Directional wells & Total \\
\hline AJ & 2 & 13 & 15 \\
MN & 2 & 0 & 2 \\
GS7 & 0 & 1 & 1 \\
GS6 & 3 & 0 & 3 \\
7 & 14 & 21 & \\
\hline
\end{tabular}


Table 11 Details of stuck problems in $17 \frac{1}{2} 2^{\prime \prime}$ hole section for vertical wells

\begin{tabular}{llcll}
\hline Cases & Formation stuck & MD of stuck & Stuck Condition & How Free Pipe \\
\hline 1 & AJ & 624 & $\begin{array}{c}\text { TRY TO CONN/OBS PIPE } \\
\text { STUCK IN UPWARD }\end{array}$ & W/BACK REAM F/624-620 m WHILE PUMP 70BBL SALT WTR \\
2 & AJ & 1214 & W\&R & FREE W/90000LBS OVERPULL \\
3 & MN & 1734 & W\&R & FREE W/80 KLB O.PULL(270 KLB ON WT. IND.), DUE TO \\
& & & TIGHT HOLE INC. MW TO 87 PCF \\
4 & MN & 1164 & POH & W/MAX 130klbs (285klbs ON WT.INDICATOR) \\
5 & GS6 & 1685 & RIH CSG & PUMP 150 BBL S.WTR \& 150 BBL F.WTR @ 2 TIMES \\
& & & POH FOR CONN & WORK ORD MAX 600 K\# ON WT.IND \\
6 & GS6 & 1026 & & TIMES, FREE PIPES W/50 k lbs OVER PULL \\
7 & GS6 & 1500 & B.REAM TO 1500 & FREE STUCK W/80000\# O.PULL W/0-3 \\
\end{tabular}

Table 12 Number of stuck pipe in $12 \frac{1}{4}$ hole based on formation

\begin{tabular}{llcc}
\hline Formation & Vertical well & Directional well & Total \\
\hline GS6 & 0 & 1 & 1 \\
GS5 & 1 & 9 & 10 \\
GS4 & 0 & 3 & 3 \\
GS3 & 0 & 2 & 2 \\
GS2 & 0 & 2 & 2 \\
CR & 2 & 4 & 6 \\
3 & 21 & 24 & \\
\hline
\end{tabular}

\section{Stuck problems in 12 1/4" hole size}

According to Table 12, directional wells accounted for 21 of the total stuck datasets in this hole size, whereas vertical wells accounted for only three. As a result, directional parameters are crucial in this part. The tangent region of the well profile is usually where a $121 / 4$ " hole is found. Furthermore, the tangent section will be tight if the mud weight is less than the acceptable amount for this part. As a result, the drilling pipes may become stuck in a tight hole. On the other side, if the KOP depth is shallow, the tangent portion of the well profile will be the long sector, increasing the chances of getting stuck. Other reasons for becoming stuck in the 12 $1 / 4$ " area, according to Fig. 3d, are differential sticking and hole cleaning processes. As shown in Table 12, most of the issues occurred in GS5 Formation. Furthermore, the majority of occurrences of stuck pipe in this hole happened during operations such as wash and ream, connection, drilling, $\mathrm{RIH}$, and $\mathrm{POH}$. Table 13 contains more information on stuck cases in the $121 / 4$ " hole section. For each stuck case, the formation name, MD of stuck, KOP, hole angle, and stuck condition are listed in this table. In addition, the techniques for releasing pipes are stated for each situation. Figure $3 \mathrm{e}$ also shows the percentage of stuck pipe for each formation in a $12 \frac{1 / 4}{4}$ hole size.

\section{Stuck problems in 8 1\%2" hole size}

The hole size of $81 / 2^{\prime \prime}$ is the most problematic, accounting for $39 \%$ of all stuck records (47 stuck cases). The occurrence of formations with varied pore pressures throughout this hole could be the fundamental reason. AS, PD, GU, and IL forms are typically found in this region. Because the AS (Asmari) formation is a depleted zone, it requires a lower mud weight. Lower formations, such as PD and GU, are high-pressure and require a lot of mud to impact the AS Formation. Differential sticking occurs in three ways in the AS Formation: permeable, porous, and depleted. As a result of these factors, differential sticking has the highest percentage of stuck types in the $81 / 2$ " hole, accounting for $50 \%$ (23 occurrences) of total points. For each formation, the average MW (mud weight) that has been used in this hole has been compared to the average MW data of observation wells in this hole (Table 14). Figure 13 shows that the average MW in stuck wells (wells with a stuck pipe) is higher in all formations when compared to observation well data. For both stuck and non-stuck situations, these data are displayed in Fig. 14 versus MD (measured depth). The AS and IL forms, with 14 and 14 stuck points, respectively, are the most challenging formations, as shown in Table 15. Other than differential sticking, there are other explanations for stuck pipe accidents in this scenario. The many causes of being stuck in this region include a tight hole difficulty and incorrect drilling parameters. Figure $3 \mathrm{f}$ and $\mathrm{g}$ indicates the percentages of stuck pipe for each formation and stuck type in 8 1/2" hole sizes, respectively. 
Table 13 Details of stuck problems in 12 1/4" hole section for directional wells

\begin{tabular}{|c|c|c|c|c|c|c|}
\hline Cases & KOP & Angle & Formation stuck & MD of stuck & Stuck Condition & How Free Pipe \\
\hline 1 & 1750 & 27 & GS6 & 2358 & WHILE CONNECTION & DECREASE MW TO 136 PCF \& PUMP PIPE LAX \\
\hline 2 & 1306 & 1 & Gs5 & 2570 & $\mathrm{POH}$ & $\begin{array}{l}80 \text { KLBS DOWNWARD APPLY TORQUE \& CIRCULATE } \\
\text { OUT } 100 \text { BBL SALT WATER }\end{array}$ \\
\hline 3 & 1204 & 32 & GS5 & 2231 & RUN SURVEY & PUMP PIPE LAX AND JARRING \\
\hline 4 & 993 & 32 & GS5 & 2314 & $\mathrm{POH}$ & NOT FREE \\
\hline 5 & 1162 & 27 & GS5 & 2495 & $\begin{array}{l}\text { WHILE } \\
\text { DRLG }\end{array}$ & W/80000 OVER PULL \& DOWN WARD \\
\hline 6 & 980 & 33.51 & GS5 & 2175 & $\begin{array}{l}\text { WHILE } \\
\text { CONN }\end{array}$ & PUMP SALT WATER \& JARRING \& OVER PULL \& \\
\hline 7 & 1165 & 28 & GS5 & 2158 & $\begin{array}{l}\text { WHILE } \\
\text { DRILLING }\end{array}$ & OVER PULL, PUMP 100 BBL SALT WATER PIPE FREE \\
\hline 8 & 540 & 22 & GS5 & 2207 & $\begin{array}{l}\text { WHILE } \\
\text { POH }\end{array}$ & $\begin{array}{l}\text { INCREASE MW TO } 144 \text { \& \& PUMP PIPE LAX \& OVER } \\
\text { PULL \& ROTATE }\end{array}$ \\
\hline 9 & 1001 & 35.4 & GS5 & 2227 & $\begin{array}{l}\text { WHILE } \\
\text { WASH \& } \\
\text { REAM }\end{array}$ & JARRING \& OVER PULL \\
\hline 10 & 980 & 33.51 & Gs5 & 2404 & $\begin{array}{l}\text { WORK } \\
\text { ON MUD } \\
\text { PUMP }\end{array}$ & GET FREE WITH OVER PULL \\
\hline 11 & 1001 & 35.4 & GS4 & 2578 & $\begin{array}{l}\text { WHILE } \\
\text { POH }\end{array}$ & FREE W/ROTATE \& PUMPING \\
\hline 12 & 1001 & 35.4 & GS4 & 2648 & $\begin{array}{l}\text { WHILE } \\
\text { GET } \\
\text { SURVEY }\end{array}$ & DECREASES MW TO 140 PCF \\
\hline 13 & 1909 & 36 & GS4 & 2612 & DRLING & OVER PULL \\
\hline 14 & 980 & 33.51 & GS3 & 2643 & $\begin{array}{l}\text { WHILE } \\
\text { TEST } \\
\text { MWD AT } \\
\text { BTM }\end{array}$ & $\begin{array}{l}\text { PUMP SALT WATER \& JARRING \& OVER PULL \& } \\
\text { TORQUE GET FREE }\end{array}$ \\
\hline 15 & 1330 & 25 & GS3 & 1993 & $\mathrm{POH}$ & PUMPED 60 BBL PIPE LAX, PIPES FREE \\
\hline 16 & 1027 & 22 & GS2 & 2610 & $\begin{array}{l}\text { DRLING } \\
\text { AND } \\
\text { RUN } \\
\text { SURVEY }\end{array}$ & PUMP 68 PCF SALT WATER \\
\hline 17 & 1330 & 25 & GS2 & 2093 & $\begin{array}{l}\text { WHILE } \\
\text { DRILLING }\end{array}$ & CIRC 60 BBL SALT WATER 72 PCF PIPE FREE \\
\hline 18 & 1001 & 35.4 & $\mathrm{CR}$ & 2626 & $\begin{array}{l}\text { WHILE } \\
\text { POH }\end{array}$ & OVER PULL \\
\hline 19 & 491 & 23 & $\mathrm{CR}$ & 2372 & $\begin{array}{l}\text { RUN } \\
\text { SINGLE } \\
\text { SHOHT }\end{array}$ & PUMP WATER \\
\hline 20 & 1385 & 23.7 & CR & 2291 & $\begin{array}{l}\text { WHILE } \\
\text { DRILLING }\end{array}$ & $\begin{array}{l}\text { WORK ON STUCK, DOWNWARD 60KLBS, OVERPULL } \\
\text { 80KLBS, JARRING, INCREASE MW } \\
\text { TO 140, CIRC SALTWATER, PIPE FREE }\end{array}$ \\
\hline 21 & 1909 & 36 & $\mathrm{CR}$ & 2682 & CIRC & PIPE LAX \\
\hline
\end{tabular}

Table 14 Values of average MW for stuck and non-stuck cases in 8 $1 / 2^{\prime \prime}$ hole

\begin{tabular}{llllll}
\hline Tittle & AS & PD & GU & IL & SV \\
\hline Stuck & 73.3 & 76.5 & 80.12 & 77.92 & 76.5 \\
Non-Stuck & 66.2 & 69 & 70.5 & 72.16 & 76 \\
\hline
\end{tabular}

\section{Stuck problems in $61 / 8^{\prime \prime}$ hole size}

Thirty-three stuck cases were discovered in $61 / 8^{\prime \prime}$ holes, with 20 cases involving vertical wells and 13 directional wells. SV and IL formations are located in this hole. In SV and IL formations, respectively, stuck pipes occurred 20 and 7 times. In this hole, there was a stuck pipe caused by many 


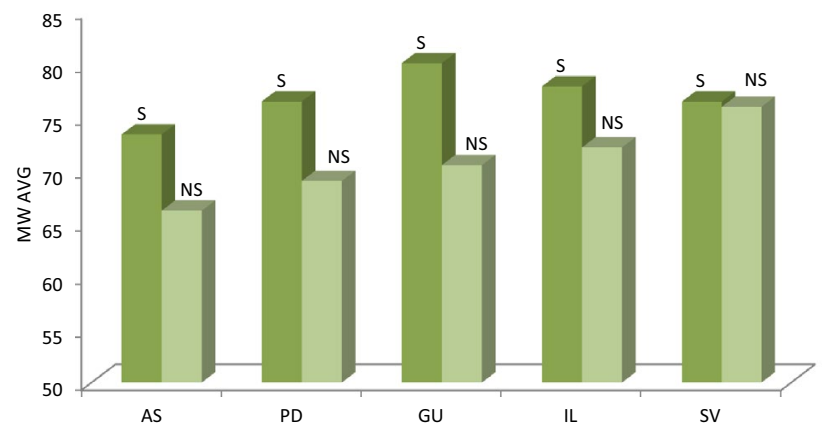

Fig. 13 Comparison of average MW for stuck and non-stuck cases in $8 \frac{1}{2}$ " hole (S means stuck condition, and NS means non-stuck state)

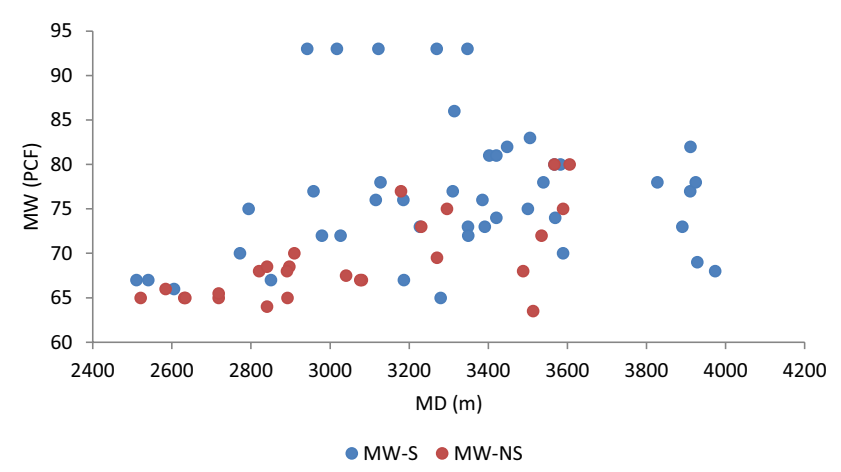

Fig. $14 \mathrm{MW}$ of stuck and non-stuck cases in $8 \frac{1}{2} 2^{\prime \prime}$ hole size versus MD (S means stuck condition, and NS means non-stuck state)

Table 15 Number of stuck pipes in $8 \frac{1 / 2}{2}$ hole based on formation

\begin{tabular}{llcc}
\hline Formation & Vertical well & Directional well & Total \\
\hline AS & 5 & 9 & 14 \\
PD & 0 & 3 & 3 \\
GU & 3 & 5 & 8 \\
IL & 7 & 7 & 14 \\
SV & 3 & 5 & 8 \\
18 & 29 & 47 & \\
\hline
\end{tabular}

mechanisms. Differential sticking, hole cleaning, tight hole mechanisms, and other mechanisms are the four types of stuck agents that can be found. The most common reasons for stuck pipes in the SV formation are inappropriate mud characteristics, hydraulic parameters, and wellbore geometry factors. Figures 15 and 16 demonstrate the percentage of stuck situations based on mechanisms and formation in this section. The number of stuck pipes in $61 / 8^{\prime \prime}$ holes is also dependent on Table 16's Formation.

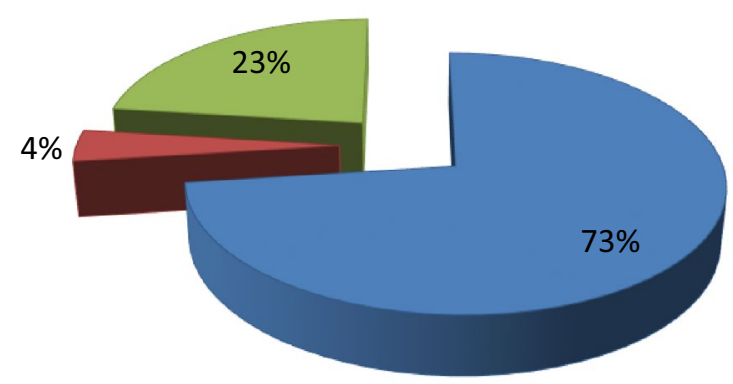

$\square$ SV $\square$ AS $\square \mathrm{IL}$

Fig. 15 Stuck pipe percentage for each formation in $61 / 8^{\prime \prime}$ hole

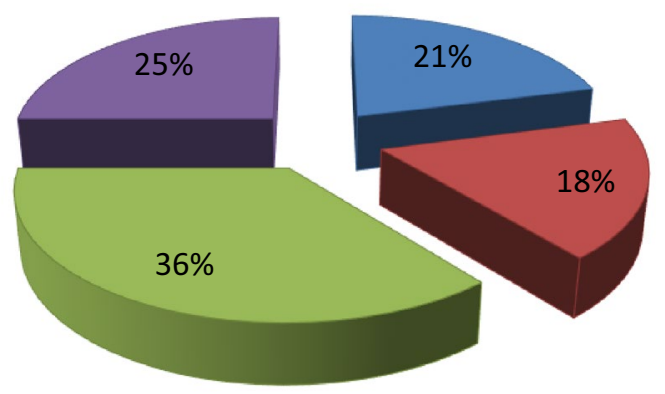

$\square$ Other Mechanisms $\square$ Hole Cleaning

$\square$ Differential $\quad \square$ Tight Hole

Fig. 16 Percentage of stuck pipe types in $61 / 8^{\prime \prime}$ hole

Table 16 Number of stuck pipe in $61 / 8^{\prime \prime}$ hole based on formation

\begin{tabular}{llcc}
\hline Formation & Vertical wells & Directional wells & Total \\
\hline AS & 0 & 1 & 1 \\
IL & 1 & 6 & 7 \\
SV & 14 & 6 & 20 \\
15 & 13 & 28 & \\
\hline
\end{tabular}

\section{Discussion and evaluation of the results of artificial neural network}

The stuck index $[0,1]$ is used in this study for stuck and non-stuck conditions. So that if the index is equal to zero and one, it indicates non-stuck and stuck, respectively. Also, in all cases, whether vertical or directional wells, if the real conditions and model were the same, then the result (outputs) will be correct for training and testing data. Tables 17 , $18,19,20,21,22$ show the results of the generated models for both datasets, vertical and directional wells. Based on 10 
Table 17 Results of PSO-based ANN model for directional wells

\begin{tabular}{|c|c|c|c|c|c|}
\hline Tittle & All data & $\begin{array}{l}\text { True } \\
\text { predic- } \\
\text { tion }\end{array}$ & $\begin{array}{l}\text { False } \\
\text { predic- } \\
\text { tion }\end{array}$ & Error $(\%)$ & Accuracy $(\%)$ \\
\hline \multicolumn{6}{|c|}{ Training data results } \\
\hline Stuck data & 63 & 53 & 10 & 15.87 & 84.13 \\
\hline $\begin{array}{l}\text { Non-stuck } \\
\text { Data }\end{array}$ & 41 & 37 & 4 & 9.75 & 90.25 \\
\hline Total data & 104 & 90 & 14 & 13.46 & 86.54 \\
\hline \multicolumn{6}{|c|}{ Testing data results } \\
\hline Stuck data & 18 & 15 & 3 & 16.66 & 83.33 \\
\hline $\begin{array}{l}\text { Non-stuck } \\
\text { data }\end{array}$ & 8 & 7 & 1 & 12.5 & 87.5 \\
\hline Total data & 26 & 22 & 4 & 15.38 & 84.61 \\
\hline
\end{tabular}

and 11 formulas, the accuracies and errors of constructed models were calculated. Tables 17 and 20 for directional and vertical datasets, respectively, exhibit these values. In addition, when employing all datasets of directional wells, Figs. 4 and 17 illustrate the predicted stuck pipe probability using the PSO-based ANN model plotted against the observed stuck pipe probability values for training and testing datasets, respectively. Figures 7 and 8 compare the predicted stuck pipe probability to the observed stuck pipe probability for the training and testing datasets, respectively, when using all vertical well datasets. The model's accuracy in predicting the chance of a stuck pipe is a good indicator of the model's performance. The accuracy of the PSO-based ANN model in directional wells is 86.54 percent for training datasets and 84.61 percent for testing datasets, indicating a close agreement between predicted and measured stuck probability. The constructed model's accuracy in vertical wells is 87.5 percent for training datasets and 80 percent for testing datasets, respectively.

\section{Directional wells}

For the model's training, 104 datasets for directional wells were randomly chosen among 130 datasets. There were 63 stuck cases out of 104 datasets and 41 non-stuck points out of 104 datasets. Table 17 shows that the accuracy of the PSO-based ANN model for all training datasets was 92.3 percent. The training data results for stuck cases demonstrate that 10 points were incorrectly predicted as non-stuck. In addition, four out of 41 non-stuck situations were misclassified as stuck cases. Eighteen data, including stuck points and remaining, belonged to non-stuck problems among the 26 datasets analyzed for directional wells testing. The model discovered that three stuck datasets had been predicted wrongly, and one non-stuck dataset had been incorrectly classified as stuck datasets, based on the training outputs. Finally, testing datasets with an accuracy of 84.61 percent show that the PSO-based ANN model's predictions for directional wells can be reasonable.

\section{Vertical wells}

For the model's training, 80 datasets for vertical wells were chosen randomly from 100 datasets. There were 37 stuck cases out of 80 datasets and 43 non-stuck points out of 80 datasets. Table 20 shows that the accuracy of the PSObased ANN model for all training datasets was 87.5 percent. The training data results for stuck cases demonstrate that two instances were incorrectly predicted as non-stuck. In addition, 8 out of 43 non-stuck situations were wrongly predicted as stuck cases. Seven data series included stuck points among the 20 datasets used as testing datasets for vertical wells, whereas the remaining 13 were non-stuck cases. The model discovered that all stuck cases were appropriately anticipated based on the testing results. Finally, testing datasets with an accuracy of $80 \%$ reveal that the PSObased ANN model's results can be suitable for vertical wells. Tables 17, 18, 19, 20, 21, 22 show that some wrong results have a little error. For example, if the real state is stuck, the stuck index should be predicted to be more than 0.5 , but the model's response is 0.45 or near 0.5 , which is erroneous.

On the other hand, some of the data in correct predicted datasets have the same problem, and in circumstances when they should be close to 1 and predict stuck conditions with high probability, they are close to 0.5 . They expect 0.55 for the stuck state, for example. The authenticity of the outcomes is low in these cases. There are numerous mechanisms and types of stuck pipes. Some settings may be effective for each stuck, while others may have no effect. Because a stuck incident is a complex topic, these low-authenticity replies may be natural for particular datasets.

\section{Conclusions}

- The results of this paper can be used in pre-drilling planning of directional and vertical wells to optimize the parameters for drilling without stuck of future wells.

- In this part, the tight hole problem is the most common kind of stuck in $171 / 2^{\prime \prime}$ hole size that may be avoided by using appropriate mud characteristics and reducing drilling time. Increased drilling time in this hole, according to DDRs, causes formation swelling. These swollen formations present an issue with tight holes.

- - In directional wells, the hole size of $121 / 4$ " is crucial. Twenty-one of the 24 stuck cases in this hole occurred in directional wells. Furthermore, all subjects were in the well profile's tangent section. Moreover, most of the issues occurred in wells where the KOP was located at

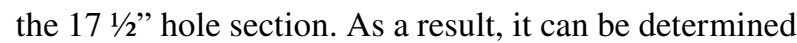

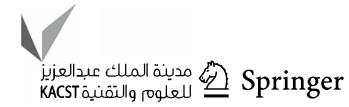


Table 18 Outputs of model for training data (directional wells)

\begin{tabular}{|c|c|c|c|c|c|}
\hline Cases & Stuck index & Real condition & Output of model & Model prediction & Result \\
\hline 1 & 0 & Non-stuck & 0.455677919 & Non-stuck & Correct \\
\hline 2 & 1 & Stuck & 0.856062533 & Stuck & Correct \\
\hline 3 & 0 & Non-stuck & 0.824569927 & Stuck & Incorrect \\
\hline 4 & 1 & Stuck & 0.428168739 & Non-stuck & Incorrect \\
\hline 5 & 0 & Non-stuck & 0.117736714 & Non-stuck & Correct \\
\hline 6 & 1 & Stuck & 0.727275516 & Stuck & Correct \\
\hline 7 & 0 & Non-stuck & 0.20476733 & Non-stuck & Correct \\
\hline 8 & 1 & Stuck & 0.755989493 & Stuck & Correct \\
\hline 9 & 1 & Stuck & 0.642455304 & Stuck & Correct \\
\hline 10 & 0 & Non-stuck & 0.180135704 & Non-stuck & Correct \\
\hline 11 & 0 & Non-stuck & 0.619287863 & Stuck & Incorrect \\
\hline 12 & 1 & Stuck & 0.379914969 & Non-stuck & Incorrect \\
\hline 13 & 1 & Stuck & 0.956272874 & Stuck & Correct \\
\hline 14 & 0 & Non-stuck & 0.447123908 & Non-stuck & Correct \\
\hline 15 & 0 & Non-stuck & 0.104071912 & Non-stuck & Correct \\
\hline 16 & 1 & Stuck & 0.96001556 & Stuck & Correct \\
\hline 17 & 1 & Stuck & 0.974351226 & Stuck & Correct \\
\hline 18 & 0 & Non-stuck & 0.122041084 & Non-stuck & Correct \\
\hline 19 & 1 & Stuck & 0.802847259 & Stuck & Correct \\
\hline 20 & 1 & Stuck & 0.804901774 & Stuck & Correct \\
\hline 21 & 1 & Stuck & 0.945365902 & Stuck & Correct \\
\hline 22 & 1 & Stuck & 0.771440238 & Stuck & Correct \\
\hline 23 & 0 & Non-stuck & 0.462639189 & Non-stuck & Correct \\
\hline 24 & 0 & Non-stuck & 0.113930935 & Non-stuck & Correct \\
\hline 25 & 1 & Stuck & 0.752743609 & Stuck & Correct \\
\hline 26 & 1 & Stuck & 0.867021437 & Stuck & Correct \\
\hline 27 & 1 & Stuck & 0.785454809 & Stuck & Correct \\
\hline 28 & 1 & Stuck & 0.807219897 & Stuck & Correct \\
\hline 29 & 1 & Stuck & 0.841962493 & Stuck & Correct \\
\hline 30 & 0 & Non-stuck & 0.392780721 & Non-stuck & Correct \\
\hline 31 & 0 & Non-stuck & 0.258235225 & Non-stuck & Correct \\
\hline 32 & 1 & Stuck & 0.761646084 & Stuck & Correct \\
\hline 33 & 1 & Stuck & 0.863710685 & Stuck & Correct \\
\hline 34 & 0 & Non-stuck & 0.585187286 & Stuck & Incorrect \\
\hline 35 & 0 & Non-stuck & 0.137203633 & Stuck & Correct \\
\hline 36 & 0 & Non-stuck & 0.114898997 & Non-stuck & Correct \\
\hline 37 & 1 & Stuck & 0.83672138 & Stuck & Correct \\
\hline 38 & 1 & Stuck & 0.762248236 & Stuck & Correct \\
\hline 39 & 0 & Non-stuck & 0.271186024 & Non-stuck & Correct \\
\hline 40 & 1 & Stuck & 0.800391493 & Stuck & Correct \\
\hline 41 & 1 & Stuck & 0.838822986 & Stuck & Correct \\
\hline 42 & 1 & Stuck & 0.355464263 & Non-stuck & Incorrect \\
\hline 43 & 1 & Stuck & 0.840391927 & Stuck & Correct \\
\hline 44 & 0 & Non-stuck & 0.139779388 & Non-Stuck & Correct \\
\hline 45 & 1 & Stuck & 0.602283951 & Stuck & Correct \\
\hline 46 & 1 & Stuck & 0.928292326 & Stuck & Correct \\
\hline 47 & 1 & Stuck & 0.849005851 & Stuck & Correct \\
\hline 48 & 1 & Stuck & 0.389370395 & Non-stuck & Incorrect \\
\hline 49 & 1 & Stuck & 0.821371518 & Stuck & Correct \\
\hline 50 & 1 & Stuck & 0.956262279 & Stuck & Correct \\
\hline 51 & 1 & Stuck & 0.255246292 & Non-stuck & Incorrect \\
\hline
\end{tabular}


Table 18 (continued)

\begin{tabular}{|c|c|c|c|c|c|}
\hline Cases & Stuck index & Real condition & Output of model & Model prediction & Result \\
\hline 52 & 1 & Stuck & 0.732152413 & Stuck & Correct \\
\hline 53 & 0 & Non-stuck & 0.075725712 & Non-stuck & Correct \\
\hline 54 & 1 & Stuck & 0.919491603 & Stuck & Correct \\
\hline 55 & 0 & Non-stuck & 0.128543965 & Non-stuck & Correct \\
\hline 56 & 0 & Non-stuck & 0.267489886 & Non-stuck & Correct \\
\hline 57 & 1 & Stuck & 0.831254448 & Stuck & Correct \\
\hline 58 & 0 & Non-stuck & 0.126449903 & Non-stuck & Correct \\
\hline 59 & 1 & Stuck & 0.60036476 & Stuck & Correct \\
\hline 60 & 1 & Stuck & 0.939049812 & Stuck & Correct \\
\hline 61 & 1 & Stuck & 0.86093922 & Stuck & Correct \\
\hline 62 & 1 & Stuck & 0.82609144 & Stuck & Correct \\
\hline 63 & 1 & Stuck & 0.678531202 & Stuck & Correct \\
\hline 64 & 1 & Stuck & 0.777028673 & Stuck & Correct \\
\hline 65 & 0 & Non-stuck & 0.163220793 & Non-stuck & Correct \\
\hline 66 & 0 & Non-stuck & 0.273581854 & Non-stuck & Correct \\
\hline 67 & 0 & Non-stuck & 0.21094496 & Non-stuck & Correct \\
\hline 68 & 1 & Stuck & 0.80338346 & Stuck & Correct \\
\hline 69 & 1 & Stuck & 0.756993164 & Stuck & Correct \\
\hline 70 & 1 & Stuck & 0.775161449 & Stuck & Correct \\
\hline 71 & 0 & Non-stuck & 0.27623341 & Non-stuck & Correct \\
\hline 72 & 1 & Stuck & 0.594685833 & Stuck & Correct \\
\hline 73 & 0 & Non-stuck & 0.137896303 & Non-stuck & Correct \\
\hline 74 & 1 & Stuck & 0.557958952 & Stuck & Correct \\
\hline 75 & 1 & Stuck & 0.824178332 & Stuck & Correct \\
\hline 76 & 0 & Non-stuck & 0.123168749 & Non-stuck & Correct \\
\hline 77 & 0 & Non-stuck & 0.080060246 & Non-stuck & Correct \\
\hline 78 & 1 & Stuck & 0.917541537 & Stuck & Correct \\
\hline 79 & 1 & Stuck & 0.630575134 & Stuck & Correct \\
\hline 80 & 1 & Stuck & 0.478164301 & Non-stuck & Incorrect \\
\hline 81 & 0 & Non-stuck & 0.637385516 & Stuck & Incorrect \\
\hline 82 & 1 & Stuck & 0.737481603 & Stuck & Correct \\
\hline 83 & 0 & Non-stuck & 0.343154533 & Non-stuck & Correct \\
\hline 84 & 1 & Stuck & 0.814635177 & Stuck & Correct \\
\hline 85 & 0 & Non-stuck & 0.26943557 & Non-stuck & Correct \\
\hline 86 & 0 & Non-stuck & 0.144218426 & Non-stuck & Correct \\
\hline 87 & 0 & Non-stuck & 0.354534984 & Non-stuck & Correct \\
\hline 88 & 1 & Stuck & 0.65433564 & Stuck & Correct \\
\hline 89 & 0 & Non-stuck & 0.518258913 & Stuck & Incorrect \\
\hline 90 & 0 & Non-stuck & 0.730407695 & Stuck & Incorrect \\
\hline 91 & 1 & Stuck & 0.702179621 & Stuck & Correct \\
\hline 92 & 1 & Stuck & 0.746140448 & Stuck & Correct \\
\hline 93 & 0 & Non-stuck & 0.52408828 & Stuck & Incorrect \\
\hline 94 & 1 & Stuck & 0.871782023 & Stuck & Correct \\
\hline 95 & 1 & Stuck & 0.931892408 & Stuck & Correct \\
\hline 96 & 1 & Stuck & 0.688120278 & Stuck & Correct \\
\hline 97 & 1 & Stuck & 0.97556287 & Stuck & Correct \\
\hline 98 & 1 & Stuck & 0.815112994 & Stuck & Correct \\
\hline 99 & 0 & Non-stuck & 0.523286245 & Stuck & Incorrect \\
\hline 100 & 0 & Non-stuck & 0.153159962 & Non-stuck & Correct \\
\hline 101 & 0 & Non-stuck & 0.141265571 & Non-stuck & Correct \\
\hline 102 & 0 & Non-stuck & 0.225174717 & Non-stuck & Correct \\
\hline
\end{tabular}


Table 18 (continued)

\begin{tabular}{llllll}
\hline Cases & Stuck index & Real condition & Output of model & Model prediction & Result \\
\hline 103 & 1 & Stuck & 0.755318846 & Stuck & Correct \\
104 & 0 & Non-stuck & 0.09045497 & Stuck & Correct \\
\hline
\end{tabular}

Table 19 Outputs of model for testing data (directional wells)

\begin{tabular}{llllll}
\hline Cases & Stuck index & Real condition & Output of model & Model prediction & Result \\
\hline 1 & 0 & Non-Stuck & 0.092659724 & Non-Stuck & Correct \\
2 & 0 & Non-Stuck & 0.44961765 & Non-Stuck & Correct \\
3 & 1 & Stuck & 0.818605139 & Stuck & Correct \\
4 & 0 & Non-Stuck & 0.171409789 & Non-Stuck & Correct \\
5 & 1 & Stuck & 0.850059593 & Stuck & Correct \\
6 & 1 & Stuck & 0.773257866 & Stuck & Correct \\
7 & 1 & Stuck & 0.849468226 & Stuck & Correct \\
8 & 1 & Stuck & 0.82033396 & Stuck & Correct \\
9 & 1 & Stuck & 0.308278723 & Non-Stuck & Incorrect \\
10 & 1 & Stuck & 0.935294999 & Stuck & Correct t \\
11 & 1 & Stuck & 0.37305197 & Non-Stuck & Incorrect \\
12 & 1 & Stuck & 0.568130612 & Stuck & Correct \\
13 & 1 & Stuck & 0.953752976 & Stuck & Correct \\
14 & 1 & Stuck & 0.7474009 & Stuck & Correct \\
15 & 0 & Non-Stuck & 0.25437701 & Non-Stuck & Correct \\
16 & 1 & Stuck & 0.876808805 & Stuck & Correct \\
17 & 0 & Non-Stuck & 0.16221331 & Non-Stuck & Correct \\
18 & 1 & Stuck & 0.957096908 & Stuck & Correct \\
19 & 0 & Non-Stuck & 0.612776683 & Non-Stuck & Correct \\
20 & 1 & Stuck & 0.767791539 & Stuck & Correct \\
21 & 0 & Non-Stuck & 0.109861168 & Stuck & Correct \\
22 & 1 & Stuck & 0.998559904 & Stuck & Correct \\
23 & 0 & Non-Stuck & 0.154825706 & Non-Stuck & Incorrect \\
24 & 1 & Stuck & 0.845904567 & Stuck & Correct \\
25 & 1 & Stuck & 0.388560045 & Non-Stuck & Incorrect \\
26 & 1 & Stuck & 0.956690122 & Stuck & Correct \\
\hline & & & & &
\end{tabular}

Table 20 Results of PSO-based ANN model for vertical wells

\begin{tabular}{lcllll}
\hline Tittle & All data & $\begin{array}{l}\text { True } \\
\text { predic- } \\
\text { tion }\end{array}$ & $\begin{array}{l}\text { False } \\
\text { predic- } \\
\text { tion }\end{array}$ & Error (\%) & Accuracy (\%) \\
& & & & & \\
\hline \multicolumn{2}{l}{ Training data results } & & & & \\
Stuck data & 37 & 35 & 2 & 5.4 & 94.6 \\
$\begin{array}{l}\text { Non-stuck } \\
\quad 43\end{array}$ & 35 & 8 & 18.6 & 81.4 \\
$\quad$ data & & & & 12.5 & 87.5 \\
$\begin{array}{l}\text { Total data } \\
\text { Testing data }\end{array}$ & 80 & 70 & 10 & 100 \\
$\begin{array}{l}\text { Stuck data } \\
\text { Non-stuck }\end{array}$ & 7 & 7 & 0 & 0 & 10 \\
$\quad$ data & 9 & 4 & 30 & 70 \\
Total data & 20 & 16 & 4 & 20 & 80 \\
\hline
\end{tabular}

that directional parameters such as KOP and angle inclination are responsible for most of the stuck issues in this segment. Optimizing these values can reduce the probability of becoming stuck in this hole.

- The most problematic hole size is $8 \frac{1}{2}$ ", and differential sticking is the most typical type of stuck in this hole. Formations could cause it with varying pore pressures on either side of the hole. In this hole, stuck pipe situations can be prevented by utilizing the appropriate MW value for each formation. In this investigation, MW values for stuck instances were higher than non-stuck cases in all $81 / 2$ " hole formations. As a result, differential sticking in this section may be caused by high mud overbalance pressure. 
Table 21 Outputs of model for training data (vertical wells)

\begin{tabular}{|c|c|c|c|c|c|}
\hline Cases & Stuck Index & Real condition & Output of model & Model prediction & Result \\
\hline 1 & 0 & Non-Stuck & 0.123242659 & Non-Stuck & Correct \\
\hline 2 & 0 & Non-Stuck & 0.055633362 & Non-Stuck & Correct \\
\hline 3 & 1 & Stuck & 0.983908065 & Stuck & Correct \\
\hline 4 & 1 & Stuck & 0.795083491 & Stuck & Correct \\
\hline 5 & 1 & Stuck & 0.863330169 & Stuck & Correct \\
\hline 6 & 1 & Stuck & 0.731941585 & Stuck & Correct \\
\hline 7 & 0 & Non-Stuck & 0.027717916 & Non-Stuck & Correct \\
\hline 8 & 0 & Non-Stuck & 0.100099324 & Non-Stuck & Correct \\
\hline 9 & 0 & Non-Stuck & 0.093552194 & Non-Stuck & Correct \\
\hline 10 & 0 & Non-Stuck & 0.229607546 & Non-Stuck & Correct \\
\hline 11 & 0 & Non-Stuck & 0.427949183 & Non-Stuck & Correct \\
\hline 12 & 1 & Stuck & 0.901156113 & Stuck & Correct \\
\hline 13 & 0 & Non-Stuck & 0.859504139 & Stuck & Incorrect \\
\hline 14 & 1 & Stuck & 0.378966818 & Non-Stuck & Incorrect \\
\hline 15 & 1 & Stuck & 0.378738139 & Non-Stuck & Incorrect \\
\hline 16 & 1 & Stuck & 0.721279105 & Stuck & Correct \\
\hline 17 & 1 & Stuck & 0.882573725 & Stuck & Correct \\
\hline 18 & 0 & Non-Stuck & 0.075752131 & Non-Stuck & Correct \\
\hline 19 & 0 & Non-Stuck & 0.144825636 & Non-Stuck & Correct \\
\hline 20 & 0 & Non-Stuck & 0.195452134 & Non-Stuck & Correct \\
\hline 21 & 1 & Stuck & 0.822977645 & Stuck & Correct \\
\hline 22 & 0 & Non-Stuck & 0.030743754 & Non-Stuck & Correct \\
\hline 23 & 1 & Stuck & 0.796848731 & Stuck & Correct \\
\hline 24 & 0 & Non-Stuck & 0.17953657 & Non-Stuck & Correct \\
\hline 25 & 1 & Stuck & 0.793953945 & Stuck & Correct \\
\hline 26 & 1 & Stuck & 0.889004699 & Stuck & Correct \\
\hline 27 & 1 & Stuck & 0.829422082 & Stuck & Correct \\
\hline 28 & 1 & Stuck & 0.588588499 & Stuck & Correct \\
\hline 29 & 0 & Non-Stuck & 0.127076508 & Stuck & Correct \\
\hline 30 & 1 & Stuck & 0.955559257 & Stuck & Correct \\
\hline 31 & 1 & Stuck & 0.839730508 & Stuck & Correct \\
\hline 32 & 0 & Non-Stuck & 0.217966714 & Non-Stuck & Correct \\
\hline 33 & 0 & Non-Stuck & 0.286380855 & Non-Stuck & Correct \\
\hline 34 & 0 & Non-Stuck & 0.271005643 & Non-Stuck & Correct \\
\hline 35 & 1 & Stuck & 0.705291997 & Stuck & Correct \\
\hline 36 & 0 & Non-Stuck & 0.86824553 & Stuck & Incorrect \\
\hline 37 & 1 & Stuck & 0.726629616 & Stuck & Correct \\
\hline 38 & 0 & Non-Stuck & 0.039046182 & Non-Stuck & Correct \\
\hline 39 & 0 & Non-Stuck & 0.314280633 & Non-Stuck & Correct \\
\hline 40 & 1 & Stuck & 0.69760685 & Stuck & Correct \\
\hline 41 & 1 & Stuck & 0.941934044 & Stuck & Correct \\
\hline 42 & 0 & Non-Stuck & 0.77242968 & Stuck & Incorrect \\
\hline 43 & 1 & Stuck & 0.883883852 & Stuck & Correct \\
\hline 44 & 1 & Stuck & 0.506008448 & Stuck & Correct \\
\hline 45 & 0 & Non-Stuck & 0.784936027 & Stuck & Incorrect \\
\hline 46 & 1 & Stuck & 0.569241721 & Stuck & Correct \\
\hline 47 & 0 & Non-Stuck & 0.311598979 & Non-Stuck & Incorrect \\
\hline 48 & 0 & Non-Stuck & 0.21247063 & Non-Stuck & Correct \\
\hline 49 & 1 & Stuck & 0.912686932 & Stuck & Correct \\
\hline 50 & 0 & Non-Stuck & 0.013752972 & Non-Stuck & Correct \\
\hline 51 & 1 & Stuck & 0.812758683 & Stuck & Correct \\
\hline
\end{tabular}


Table 21 (continued)

\begin{tabular}{|c|c|c|c|c|c|}
\hline Cases & Stuck Index & Real condition & Output of model & Model prediction & Result \\
\hline 52 & 1 & Stuck & 0.609959859 & Stuck & Correct \\
\hline 53 & 1 & Stuck & 0.715122233 & Stuck & Correct \\
\hline 54 & 1 & Stuck & 0.889765717 & Stuck & Correct \\
\hline 55 & 1 & Stuck & 0.885759861 & Stuck & Correct \\
\hline 56 & 0 & Non-Stuck & 0.37427521 & Non-Stuck & Correct \\
\hline 57 & 1 & Stuck & 0.762874786 & Stuck & Correct \\
\hline 58 & 0 & Non-Stuck & 0.647149785 & Stuck & Incorrect \\
\hline 59 & 1 & Stuck & 0.708049583 & Stuck & Correct \\
\hline 60 & 0 & Non-Stuck & 0.894168601 & Stuck & Incorrect \\
\hline 61 & 0 & Non-Stuck & 0.179913662 & Non-Stuck & Correct \\
\hline 62 & 1 & Stuck & 0.796778705 & Stuck & Correct \\
\hline 63 & 1 & Stuck & 0.734167915 & Stuck & Correct \\
\hline 64 & 1 & Stuck & 0.700810696 & Stuck & Correct \\
\hline 65 & 1 & Stuck & 0.7439268 & Stuck & Correct \\
\hline 66 & 1 & Stuck & 0.783638647 & Stuck & Correct \\
\hline 67 & 1 & Stuck & 0.905487941 & Stuck & Correct \\
\hline 68 & 1 & Stuck & 0.91951559 & Stuck & Correct \\
\hline 69 & 0 & Non-Stuck & 0.253511245 & Non-Stuck & Correct \\
\hline 70 & 0 & Non-Stuck & 0.258208273 & Non-Stuck & Correct \\
\hline 71 & 1 & Stuck & 0.823414555 & Stuck & Correct \\
\hline 72 & 0 & Non-Stuck & 0.056650837 & Non-Stuck & Correct \\
\hline 73 & 1 & Stuck & 0.735967442 & Stuck & Correct \\
\hline 74 & 0 & Non-Stuck & 0.222642407 & Non-Stuck & Correct \\
\hline 75 & 0 & Non-Stuck & 0.871166733 & Stuck & Incorrect \\
\hline 76 & 1 & Stuck & 0.688247096 & Stuck & Correct \\
\hline 77 & 1 & Stuck & 0.984500011 & Stuck & Correct \\
\hline 78 & 0 & Non-Stuck & 0.682582592 & Stuck & Incorrect \\
\hline 79 & 0 & Non-Stuck & 0.165441867 & Non-Stuck & Correct \\
\hline 80 & 0 & Non-Stuck & 0.034428417 & Non-Stuck & Correct \\
\hline
\end{tabular}


Table 22 Outputs of model for testing data (vertical wells)

\begin{tabular}{llllll}
\hline Cases & Stuck index & Real condition & Output of model & Model prediction & Result \\
\hline 1 & 0 & Non-Stuck & 0.873344101 & Stuck & Incorrect \\
2 & 0 & Non-Stuck & 0.886493612 & Stuck & Incorrect \\
3 & 0 & Non-Stuck & 0.102873011 & Non-Stuck & Correct \\
4 & 1 & Stuck & 0.822704913 & Stuck & Correct \\
5 & 1 & Stuck & 0.753485276 & Stuck & Correct \\
6 & 0 & Non-Stuck & 0.165074593 & Non-Stuck & Correct \\
7 & 1 & Stuck & 0.847515037 & Stuck & Correct \\
8 & 0 & Non-Stuck & 0.178833314 & Non-Stuck & Correct \\
9 & 0 & Non-Stuck & 0.72327172 & Stuck & Incorrect \\
10 & 0 & Non-Stuck & 0.093116891 & Non-Stuck & Correct \\
11 & 0 & Non-Stuck & 0.146519103 & Non-Stuck & Correct \\
12 & 0 & Non-Stuck & 0.196671306 & Non-Stuck & Correct \\
13 & 0 & Non-Stuck & 0.250719206 & Non-Stuck & Correct \\
14 & 1 & Stuck & 0.898326035 & Stuck & Correct \\
15 & 1 & Stuck & 0.851301145 & Stuck & Correct \\
16 & 1 & Stuck & 0.941177713 & Stuck & Correct \\
17 & 1 & Stuck & 0.850894111 & Stuck & Correct \\
18 & 0 & Non-Stuck & 0.068476201 & Non-Stuck & Correct \\
19 & 0 & Non-Stuck & 0.048431599 & Non-Stuck & Correct \\
20 & 0 & Non-Stuck & 0.71872653 & Non-Stuck & Incorrect \\
\hline & & & &
\end{tabular}

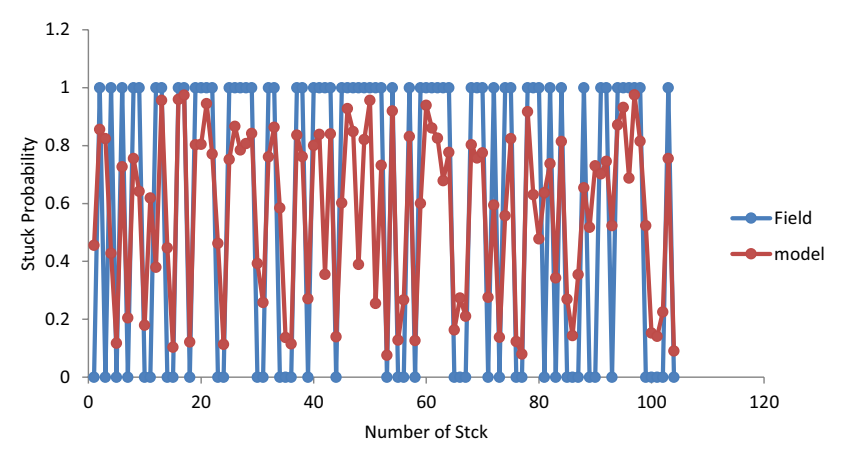

Fig. 17 The Flow Chart of PSO Algorithm

- It can be stated that geometry parameters considerably affect the model's performance for directional wells based on the input parameters for two groups, vertical and directional wells. In vertical circumstances, however, mud qualities are more essential.

- The suggested model may estimate stuck pipe probability during well development in the desired field. It has a reasonable accuracy of over $80 \%$ for directional and vertical wells.

- The performance of ANN models can be improved by reducing the number of input parameters. New dimensionless parameters were defined in this work by merging some parameters. The addition of new parameters improved the network's findings.
- Optimization of PSO and neural network parameters has a substantial impact on the performance of a PSO-based ANN model.

Funding The authors state that no funds were allocated to this research paper.

\section{Declarations}

Conflict of interest The corresponding author states that there is no conflict of interest on behalf of all authors.

Open Access This article is licensed under a Creative Commons Attribution 4.0 International License, which permits use, sharing, adaptation, distribution and reproduction in any medium or format, as long as you give appropriate credit to the original author(s) and the source, provide a link to the Creative Commons licence, and indicate if changes were made. The images or other third party material in this article are included in the article's Creative Commons licence, unless indicated otherwise in a credit line to the material. If material is not included in the article's Creative Commons licence and your intended use is not permitted by statutory regulation or exceeds the permitted use, you will need to obtain permission directly from the copyright holder. To view a copy of this licence, visit http://creativecommons.org/licenses/by/4.0/.

\section{References}

Ahmadi MA (2012) Neural network based unified particle swarm optimization for prediction of asphaltene precipitation. Fluid Phase Equilib 314:46-51. https://doi.org/10.1016/j.fluid.2011.10.016 
Ahmadi MA (2015) Developing a robust surrogate model of chemical flooding based on the artificial neural network for enhanced oil recovery implications. Math Model Anal Soft Comput. https://doi. org/10.1155/2015/706897

Ahmadi MA, Chen Zh (2020) Machine learning-based models for predicting permeability impairment due to scale deposition. J Pet Explor Prod Technol 10:2873-2884. https://doi.org/10.1007/ s13202-020-00941-1

Ahmadi MA, Bahadori A, Shadizadeh SR (2015) A rigorous model to predict the amount of dissolved calcium carbonate concentration throughout oil field brines: side effect of pressure and temperature. Fuel. https://doi.org/10.1016/j.fuel.2014.08.044

Al-Baiyat IA, Heinze L (2012) Implementing Artificial Neural Networks and Support Vector Machines in Stuck Pipe Prediction. In: S.P.E. Kuwait International Petroleum Conference and Exhibition, Kuwait City, Kuwait. https://doi.org/10.2118/163370-MS

Al-Dushaishi MF, Abbas AK, Alsaba M, Abbas H, Dawood J (2020) Data-driven stuck pipe prediction and remedies. Upstream Oil and Gas Technol 6:1-9. https://doi.org/10.1016/j.upstre.2020.100024

Alshaikh A, Magana-Mora A, Gharbi SA, Al-Yami A (2019). Machine learning for detecting stuck pipe incidents: data analytics and models evaluation. Society of Petroleum Engineers, International Petroleum Technology Conference, Beijing, China. https://doi.org/ 10.2523/IPTC-19394-MS

Amin SM, Rodin EY (1998) Neurocontrol of nonlinear system via local memory neurons. Math Comput Model 27(3):65-92. https://doi. org/10.1016/S08957177(97)00266-5

Biegler M, Kuhn G (1994) Advances in prediction of stuck pipe using multivariate statistical analysis. Paper IADC/SPE 27529 presented at the IADC/SPE Drilling Conference, Dallas, Texas, U.S.A., 15-18 February

Chamkalani A, Pordel Shahri M, Poordad S (2013) Support vector machine model: a new methodology for stuck pipe prediction. In: Paper SPE 164003 presented at the Middle East Unconventional Gas Conference and Exhibition held in Muscat, Oman, 28-30 January

Dupriest FE, Elks WC, Ottesen S (2011) Design methodology and operational practices eliminate differential sticking. In: IADC/ SPE drilling conference and exhibition, New Orleans, Louisiana, U.S.A. https://doi.org/10.2118/128129-MS

Efteland F, Creegan A, Jordan L, Caraway C. (2015). The significance of pro-active online monitoring with stick-slip mitigation. Society of Petroleum Engineers, Abu Dhabi International Petroleum Exhibition and Conference, Abu Dhabi, U.A.E. https://doi.org/ 10.2118/177950-MS

Elmabrouk SK (2012). Application of function approximations to reservoir engineering. Ph.D. thesis. Department of Petroleum Engineering, University of Regina

Gola G, Nybø R, Sui D, Roverso D (2012) Improving management and control of drilling operations with artificial intelligence. In: S.P.E. Intelligent Energy International, Utrecht, The Netherlands. https:// doi.org/10.2118/150201-MS

Gulsrud TO, Nybø R, Bjørkevoll KS (2009) Statistical method for detection of poor hole cleaning and stuck pipe. S.P.E. Offshore Europe Oil and Gas Conference and Exhibition, Aberdeen, U.K. https://doi.org/10.2118/123374-MS

Hassan R, Cohanim B, De Weck O, Venter G (2005) A comparison of particle swarm optimization and the genetic algorithm. In:46th AIAA/ASME/ASCE/AHS/ASC structures, structural dynamics and materials conference. https://doi.org/10.2514/6.2005-1897

Hegde C, Wallace S, Gray K (2015). Using trees, bagging, and random forests to predict rate of penetration during drilling. In: S.P.E. Middle east intelligent oil and gas conference and exhibition, Abu Dhabi, U.A.E. https://doi.org/10.2118/176792-MS
Hegde C, Gray KE (2017) Use of machine learning and data analytics to increase drilling efficiency for nearby wells. J Nat Gas Sci Eng 40:327-335. https://doi.org/10.1016/j.jngse.2017.02.019

Hempkins WB, Kingsborough RH, Lohec WE, Nini CJ (1987) Multivariate statistical analysis of stuck drillpipe situations. SPE Drill Eng 2(3):237

Hunter G, Ollerenshaw A (2014) Stuck pipe non-productive time reduction by application of intelligent technologies to replace conventional drillstring separation methods. Offshore Technol Conference-Asia, Kuala Lumpur, Malaysia. https://doi.org/10. 4043/25053-MS

K. Abbas A, Flori A, Almubarak H, Dawood J, Abbas H, Alsaedi A. (2019). Intelligent prediction of stuck pipe remediation using machine learning algorithms. In: S.P.E. Annual technical conference and exhibition, Calgary, Alberta, Canada. https://doi.org/10. 2118/196229-MS

Magana-Mora A, Gharbi S, Alshaikh A, Al-Yami A (2019). AccuPipePred: a framework for the accurate and early detection of stuck pipe for real-time drilling operations. In: S.P.E. Middle East Oil and Gas Show and Conference, Manama, Bahrain. https://doi.org/ 10.2118/194980-MS

Miri R, Sampaio J, Afshar M (2007) Development of artificial neural networks to predict differential pipe sticking in iranian offshore oil fields. Paper SPE 108500 presented at the International Oil Conference and Exhibition, Veracruz, Mexico, 27-30 June

Muqeem MA, Weekse AE, Al-Hajji AA. (2012). Stuck pipe best practices: a challenging approach to reducing stuck pipe costs. In: S.P.E. Saudi arabia section technical symposium and exhibition, society of petroleum engineers, Al-Khobar, Saudi Arabia. https:// doi.org/10.2118/160845-MS

Murillo A, Neuman J (2009). Pipe sticking prediction and avoidance using adaptive fuzzy logic and neural network modeling. S.P.E. Production and operations symposium, Oklahoma City, Oklahoma. https://doi.org/10.2118/120128-MS

Murillo A, Neuman J, Samuel R (2009) Pipe sticking prediction and avoidance using adaptive fuzzy logic modeling. In: S.P.E. Production and Operations Symposium, Oklahoma City, Oklahoma. https://doi.org/10.2118/120128-MS

Nybo R, Sui D. (2014). Closing the integration gap for the next generation of drilling decision support systems. In: S.P.E. intelligent energy conference \& exhibition, Utrecht, The Netherlands. https:// doi.org/10.2118/167864-MS

Nybø R (2009). Efficient Drilling Problem Detection. Ph.D. thesis, NTNU, Trondheim, Norway

Wallace S, Hegde C, Gray K (2015) A system for real-time drilling performance optimization and automation based on statistical learning methods. In: S.P.E. Middle East intelligent oil and gas conference and exhibition, Abu Dhabi, U.A.E. https://doi.org/10. 2118/176804-MS

Salminen K, Cheatham C, Smith M, Valiulin K (2016). Stuck pipe prediction using automated real-time modeling and data analysis. In: IADC/SPE Drilling Conference and Exhibition, Fort Worth, Texas, U.S.A. https://doi.org/10.2118/178888-MS

Shadizadeh SR, Karimi F, Zoveidavianpoor M (2010) Drilling stuck pipe prediction in iranian oil fields: an artificial neural network approach. Iran J Chem Eng 7(4):29-41

Shoraka SAR, Shadizadeh SR, Shahri MP (2011) Prediction of stuck pipe in Iranian south oil fields using multivariate statistical analysis. Niger Annu Int Conf Exhib. https://doi.org/10.2118/ 151076-MS

Siruvuri C, Nagarakanti S, Samuel R (2006) Stuck pipe prediction and avoidance: a convolutional neural network approach. IADC/SPE Drilling Conference, Miami, Florida, U.S.A. https://doi.org/10. 2118/98378-MS

Solberg SM (2012). Improved drilling process through the determination of hardness and lithology boundaries. Norwegian University 
of Science and Technology, Department of Petroleum Engineering and Applied Geophysics, Master's thesis

Sui D, Nybø R, Gola G, Roverso D, Hoffmann M (2011) Ensemble methods for process monitoring in oil and gas industry operations. J Nat Gas Sci Eng 3(6):748-753. https://doi.org/10.1016/j. jngse.2011.05.004

Sui D, Nybø R, Hovland S, Johansen TA (2012) A moving horizon observer for estimation of bottomhole pressure during drilling. IFAC Proc Volum Norwegian University Sci Technol Trondheim, Norway. https://doi.org/10.3182/20120531-2-NO-4020.00024

Sui D, Nybø R, Azizi V. (2013). Real-time optimization of rate of penetration during drilling operation. In: 10th IEEE international conference on control and automation (ICCA), Hangzhou, China. https://doi.org/10.1109/ICCA.2013.6564893

Zhang JR, Zhang J, Lok TM, Lyu MR (2007) A hybrid particle swarm optimization-backpropagation algorithm for feedforward neural network training. Appl Math Comput 185(2):1026-1037. https:// doi.org/10.1016/j.amc.2006.07.025

Publisher's Note Springer Nature remains neutral with regard to jurisdictional claims in published maps and institutional affiliations. 